\title{
A Novel Method to Estimate the Damage Severity Using Spatial Wavelets and Local Regularity Algorithm
}

\author{
Arun Kumar K*, Mallikarjuna Reddy D \\ VIT University, India \\ 6nkumar.vnn@gmail.com,bttps://orcid.org/0000-0002-3742-4136 \\ dmreddy@vit.ac.in
}

ABSTRACT. In the process of structural damage detection using continuous wavelet transform (CWT), the perturbation or damage is located by identifying the defects locally in the input signal data. In this work the damage identification procedure using continuous wavelet transform is developed. This method is studied numerically using a simple beam model. The influence of reduced spatial sampling using fundamental mode shape is investigated in detail. The method is also investigated to ascertain the smallest level of damage identified using strain energy mode shape data.

KEYwORDS. Mode shapes; Wavelet; Structural damage detection; Hoelder exponent; Local regularity.

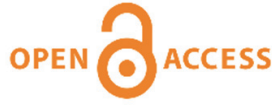

Citation: Kumar K., A., Reddy D., M., A Novel Method to Estimate the Damage Severity Using Spatial Wavelets and Local Regularity Algorithm, Frattura ed Integrità Strutturale, 54 (2020) 36-55.

Received: 19.04 .2020

Accepted: 12.08 .2020

Published: 01.10.2020

Copyright: (C) 2020 This is an open access article under the terms of the CC-BY 4.0, which permits unrestricted use, distribution, and reproduction in any medium, provided the original author and source are credited.

\section{INTRODUCTION}

$\mathrm{S}$ tructural condition monitoring is an effective method of diagnosing damage and to keep the structure safe. Damage identification using vibration based techniques is better than the traditional method, when the mode shape based and frequency based damage detection are not able to detect the small defect. Wavelet method is used to detect the crack for this process only spatial data is enough. Cawley and Adams [1] showed how to utilize the dynamic characteristics in damage detection based on natural frequency method. Salawu and Williams [4] reviewed mode shape based damage detection. Quan and Xiamin [6] explained if the defect present in the structure, dynamic behavior changes at damage location. Boulahbal et al. [7] Utilized wavelet transform to detect damage in gear test ring with assist of polar representation. Ratcliff [9] explained mode shape curvature based damage detection. Tong et al. [10] Tested sensitivity of Haar and Gabor wavelet, Haar wavelet is best for beam damage detection. Douka et al. [11] analyzed a damaged cantilever beam structure with continuous wavelet transform and suggested the absolute wavelet transform value shows nearer to damage severity and also the results are proven by both analytically and experimentally for a transverse surface damage cantilever beam. Hani and Hasang [12] explained the features of Continuous wavelet transforms, it is having good potential over Fast Fourier Transform in damage detection. Continuous Wavelet transform (CWT) is capable to identify the damage in concrete. Chang and Chen [13] implement the wavelet transform technique in Timoshenko beam and proved this method is detecting the small size defect. Loutridisa et al. [14] proposed Double cracked beam structure; damage is detected by symlet wavelet. Chang and Chen [15] suggested the Continuous wavelet transform are able to detect the multi damage in structure. Rucka and Wilde [16] suggested this method is suitable for bridge like structure, and shows the effective of continuous wavelet 
transform in the process of damage detection. Reddy and Swarnamani [17] proposed Frequency response function curvature energy based damage index for damage detection in plate like structures. Reddy and Swarnamani [18] discussed how the strain energy modal data is processed through wavelet method and the effectiveness of the wavelet transform in the damage detection in beam and plate like structure explained. Katunin and Holewik [19] discussed the wavelet decomposition and reconstruction how useful in damage detection. Khoram et al. [20] applied CWT to detect damage in simple beam with dynamic load. Xiang et al. [21] presented hybrid damage detecting method implemented to conical shell. Katunin [22] suggested 2D Wavelet transform tool for damage localization in sandwich structure. Mehrjoo et al. [23] proposed inversed approach using genetic algorithm for damage detection. Feng and Liu [24] explained novel waveform method to detect damage. Katunin et al. [25] implemented automated technique in damage detection. Jaiswal and Pande [26] explained the analytical method for crack localization in beam structure with help of curvature of mode shape method and its spatial or modal wavelet transforms are discussed. Diaterio and Sepe [27] considered Multi-span and multi-floor framed structures and analyzed by means of a substructures approach, analyzing complicated structure experimentally is challenging and more sensors require. Gholizad and Safari [28] proposed new idea that was experimental modal shape data processed through 2D wavelet transform to identify the damage location present in the plates. Janeliukstis et al., [29] Complex Morlet wavelet function adapted for damage detection problem, proposed method is effective even in the noisy situation. Mardasi et al. [30] Gabor wavelet function implemented in beam damage detection problem, proper windowing functions will give the optimal results. Abdul Kareem et al.,[32] compares the discrete wavelet transform and continuous wavelet transform for structural connectivity problem, the end results shows the continuous wavelet transform is better than discrete wavelet transform. Akbari et al.[33] when noisy situation discrete wavelet transform is not effective alone same as like teager energy operator,, but once it combined means the efficiency of the proposed method is reliable.

Based on the extensive study of existing damage detection methods based on vibration data natural frequency, mode shapes and strain energy data's are used as an input for damage detection algorithm. But the damage level is not significant then some additional techniques need to improve the damage detection method, the continuous wavelet transform is most suitable function to improve the damage detection sensitivity. The main objective of the study is focusing continuous wavelet transform and hoelder exponent technique implement for beam structure. Most of the literature reviews focus on beam and plate structure because in real life most of the structural shapes are related to beam and plates. This paper focuses to improve the damage detection algorithm on beam damage detection algorithm when mode shapes loses its sensitivity on damage detection the difference mode shape data utilized, even the difference data based damage detection algorithm is not effective particularly the damage severity is less so the difference strain energy data used to improve damage detection algorithm effectively, The single and double damage identification problem solved. Spatial points sampling method also focused to identify the minimum positions to get the responses during the experimental analysis. Free-free boundary conditions considered for this study the modal analysis were carried out in ANSYS the Timoshenko beam element consider for the analysis. Wavelet coefficient are calculated by the MATLAB [31].

\title{
CWT BASED DAMAGE IDENTIFICATION ALGORITHM: METHODOLOGY
}

\begin{abstract}
7 he spatial signal is convolved with mother wavelet (e.g., Gaussian Wavelets) for different wavelet scales to get a matrix of wavelet coefficients. The rows and column of the coefficient matrix are respectively equal to the size of spatial signal and the number of wavelet scales. Damage can be detected and located by plotting a 3-D graph of wavelet coefficients in scale-translation (Node/element number or length of beam) plane. Any point of high wavelet coefficients on the translation axis, indicate damage and the position of the same helps in locating the damage. Once damage is located, damage is quantified by collecting the high value of wavelet coefficients near the damaged position for a number of values of scale. The variation of these maximum wavelet coefficients with scales is plotted both in logarithmic axes. The data is linear fitted to get the slope data and y axis intercept of the line. From the obtained data set of slope and respective $\mathrm{y}$-intercept of line the intensity factor and Hoelder exponent are estimated. The same procedure can be repeated for different damage severity.
\end{abstract}

\section{WAVELET TRANSFORM}

he wavelet transform is a conversion that decomposes a function $\mathrm{X}(\mathrm{T})$ into a superposition of the elementary function $\Psi_{r, s}(T)$ derived from an analyzing wavelet $\Psi(T)$ by scaling and translating, as defined below: 


$$
\Psi_{r, s}=|r|^{1 / 2} \Psi\left(\frac{T-s}{r}\right)
$$

' $\mathrm{s}$ ' is the translation factor indicating the position and ' $\mathrm{r}$ ' is the scale factor. The time scale wavelet transform of the signal $\mathrm{X}(\mathrm{T})$ is defined

$$
W_{\bar{\Psi}}(\mathrm{r}, \mathrm{s})=\int_{-\infty}^{\infty} X(T) \bar{\Psi}_{r, s}(T) d T
$$

the $\bar{\Psi}($.$) is the complex conjugate of \Psi(.) W_{\bar{\Psi}}(r, s)$ is called the wavelet coefficient for the wavelet $\Psi_{r, s}(T)$.

Wavelets are usually used to analyze the signal in the time domain. However, by replacing time variable $\mathrm{T}$ with spatial coordinates then spatially distributed signals can be analyzed with wavelets. For square-integrable signals $f(X)$, the continuous Wavelet Transform (CWT) Wf is defined

$$
\mathrm{Wf}(\mathrm{e}, \mathrm{d})=\int_{-\infty}^{\infty} f(X) \Psi_{e, d}{ }^{*}(X) d X=\int_{-\infty}^{\infty} f(X) \frac{1}{\sqrt{d}} \Psi^{*}\left(\frac{X-e}{d}\right) d X
$$

where $\Psi^{*}(X)$ is the conjugate of the mother wavelet $\Psi(X)$. The function $\Psi_{e, d}(X)$ is dilated by the scaling parameter, ' $\mathrm{d}$ ' and translated by the translation parameter, 'e' of the mother wavelet $\Psi(x)$

Wavelet coefficients are executed using by scale functions, local variations in the mode shape data is identified in the lower level scale wavelets that are placed at the location of the changes in slope due to damage. The wavelet method can identify and characterize transients in a modal or spatial signal data with zooming method for range of scales. Sharp transients provide high value of wavelet coefficients. Thus, highest value of wavelet coefficients $\mathrm{W} \mathrm{f}(\mathrm{a}, \mathrm{b})$ at a specified location on the modal or spatial data signal senses and identify the damage.

\section{Wavelet transform with local regularity function}

Continuous wavelet transform can be used to identify the local smoothness, it can be estimated by Hoelder exponent function. A signal is regular and it can be locally calculated by using a polynomial expression. The Hoelder exponent is used to measure local regularity in the input signal Mallat \& Hwang [3]

The $f(x)$ is a function it has a Hoelder exponent $\alpha \geq 0$ at $\mathrm{x}=\mathrm{v}$, if there is availability of a constant $\mathrm{C}>0$ and respective polynomial expressed as $p_{v}$ of degree $n$ (where $n$ is largest number satisfying $n \leq \alpha$ ) such that

$$
\left|f(x)-p_{v}\right| \leq C|x-v|^{\alpha}
$$

$p(x)$ is related with to Taylor series expansion of function $f(x)$ at $v$.

By observing the variation of wavelet maxima $|W f(u, s)|$ coefficients as scale (s) tends to zero, it can be demonstrated for singularities, the wavelet maxima value follows an exponential law with an exponent equal to Hoelder exponent highlighted as follows

$$
|W f(u, s)| \leq C s^{\alpha+(1 / 2)}
$$

Sudden changes of an input data cause local maximum at one scale value of the modulus mode of wavelet transform process. The changes of maxima modulus data along maximum modulus slope are estimated by Hoelder exponent. Rearranging the Eqn. 5 in logarithmic form given by:

$$
\log _{2}|W f(u, s)| \leq \log _{2} C+\left(\alpha+\frac{1}{2}\right) \log _{2} S
$$

where ' $\alpha$ ' represents Hoelder exponent and $\mathrm{C}$ is a constant value known as intensity factor. Above equation represents a straight line equation with slope $(\alpha+1 / 2)$ and $y$ intercept $\log _{2} C$. The Hoelder exponent provides the info about function differentiability with more accurately. 


\section{NUMERICAL STUDY}

A beam with dimensions $\mathrm{L}=1200 \mathrm{~mm}, \mathrm{~b}=20 \mathrm{~mm}, \mathrm{~h}=20 \mathrm{~mm}$ is considered as Finite element model Modulus of elasticity $69.8 \mathrm{GPa}$ and the mass density $\sigma=2600 \mathrm{~kg} / \mathrm{m}^{3}$, Poisson's co efficient is 0.33 . The beam is discretized into 2400 one-dimensional elements. At a distance of $800 \mathrm{~mm}$ from left end damage is simulated for $1600^{\text {th }}$ element as highlighted in Fig. 1. The damage case $(\mathrm{c} / \mathrm{h})$ is varied from 0.1 to 0.9 to give various damage scenarios. The both end of the beam are free boundary conditions. Damage is modeled by changing the area moment of inertia of a particular element in the Finite element (FE) model. 3D beam element (2 noded 188) element selected for modal analysis through ANSYS. The element theory was developed based on Timoshenko beam theory it assumes first order shear deformation theory.
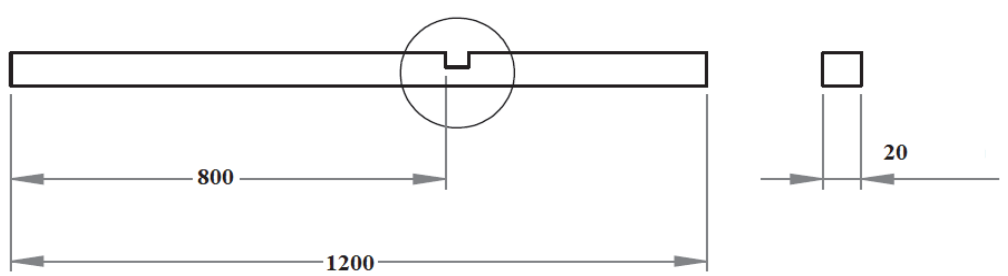

(a)

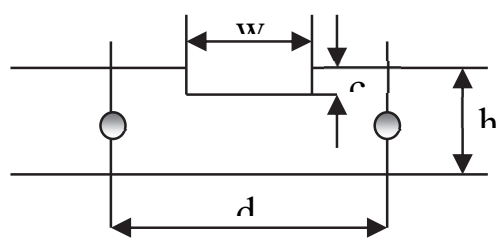

(b)

Figure 1: Beam with geometry of damage simulation

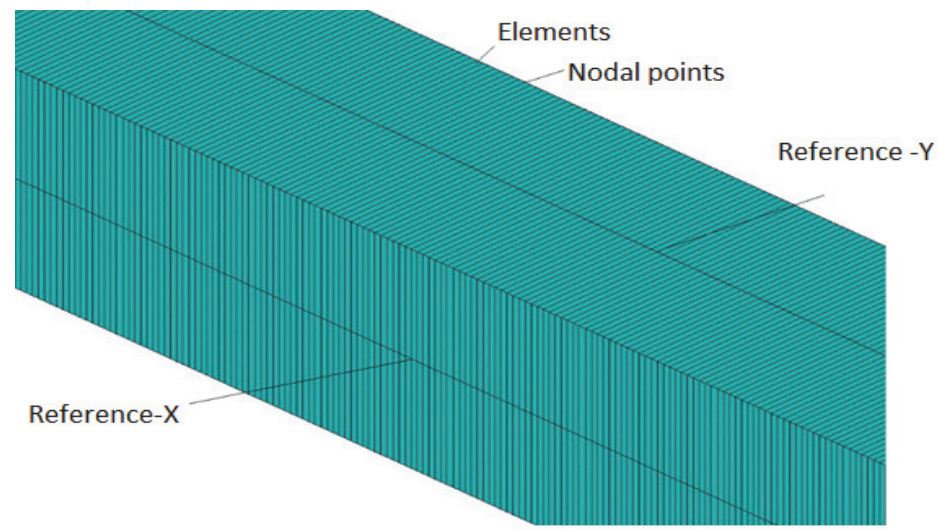

Figure 2: Finite element meshed model of beam

' $\mathrm{d}$ ' is spatial sampling along the length of the beam and ' $w$ ' is dimension of damage or cut of an damaged element it is 0.5 $\mathrm{mm}$ and it is one element size shown in Fig. 1(b). Fig. 2 shows the finite element meshed model of the proposed beam model. To select the optimum number elements the convergence study carried out. From the Tab. 1 first three cases the first two natural frequencies are not varying but the third mode natural frequency is changing because it is higher mode. Comparing all other cases the element size increases the natural frequency variances is high on the other hand the number of elements decreasing the natural frequency is increasing. The main objective of the study is to detect the least amount of damage so here 2400 number of elements are chosen for this study because in this case the natural frequency is low so it is the challenging task. 


\begin{tabular}{llllll}
\hline S. No & $\begin{array}{l}\text { Number of } \\
\text { Elements }\end{array}$ & $\begin{array}{l}\text { Element Size } \\
(\mathrm{mm})\end{array}$ & $\begin{array}{l}\text { First mode } \\
\text { Natural } \\
\text { Frequency }\end{array}$ & $\begin{array}{l}\text { 2 mode } \\
\text { Natural } \\
\text { Frequency }\end{array}$ & $\begin{array}{l}\text { Third mode } \\
\text { Natural Frequency }\end{array}$ \\
$\mathbf{1}$ & 2400 & 0.5 & 72.56 & 199.87 & 391.51 \\
$\mathbf{2}$ & 1200 & 1 & 72.56 & 199.87 & 391.52 \\
$\mathbf{3}$ & 600 & 2 & 72.56 & 199.87 & 391.53 \\
$\mathbf{4}$ & 300 & 4 & 72.57 & 199.88 & 391.56 \\
$\mathbf{5}$ & 150 & 8 & 72.61 & 199.92 & 391.72 \\
$\mathbf{6}$ & 120 & 10 & 72.64 & 199.95 & 391.83 \\
$\mathbf{7}$ & 60 & 20 & 72.66 & 200.17 & 393.11 \\
$\mathbf{8}$ & 30 & 40 & 73.014 & 201.08 & 396.93 \\
$\mathbf{9}$ & 15 & 80 & 73.365 & 204.72 & 411.52 \\
\hline
\end{tabular}

Table 1: Convergence study.

Using finite element tool, Modal analysis is carried out to acquire the initial three natural frequencies and respective mode shapes signals for all different damage scenarios or cases as highlighted in Tab. 2. To identify the variation in frequency values due to damage severity when compared to frequency of healthy beam. Fig. 3(a) highlights the graph of normalized value of natural frequency for initial three modes with different damage scenarios $(\mathrm{c} / \mathrm{h})$. $\mathrm{c}$ denotes damage severity, h denotes width of the beam.
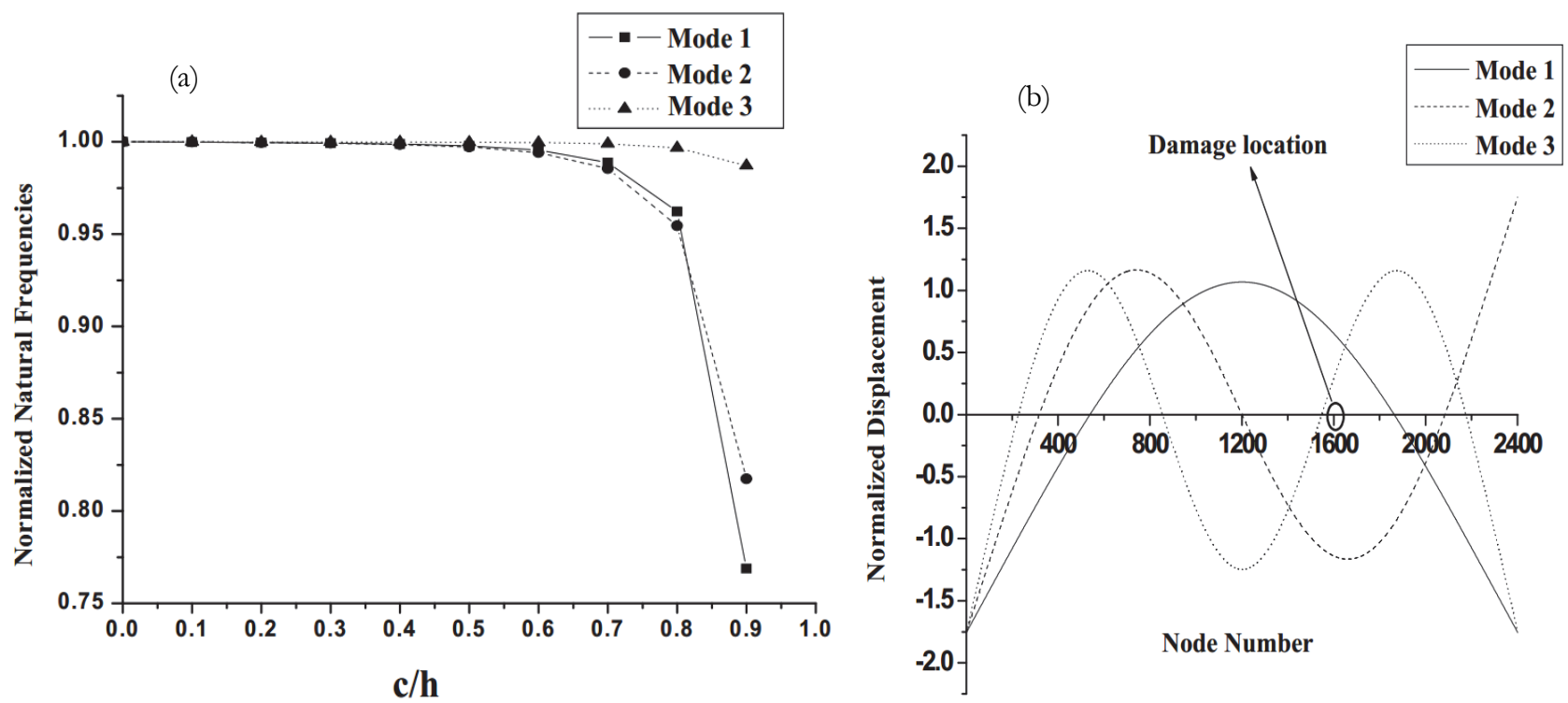

Figure 3: sensitivity of damage on natural frequencies (a) Comparison of natural frequencies first three modes shapes for both undamaged and damages cases (b) Location of damages element in three mode shapes

The frequencies of all damage scenarios corresponding to specific mode is normalized with respect to undamaged natural frequency. It is clearly shown that change in the frequency values for $2^{\text {nd }}$ mode is high compared to other frequencies. This is because of anti-nodal point of $2^{\text {nd }}$ mode almost nearer to damage position. The shift in frequency value is less for $3^{\text {rd }}$ mode due to occurrence of nodal point of mode closure to the damaged $1600^{\text {th }}$ node as observed in Fig. 3(b). 


\begin{tabular}{lccc}
\hline \multicolumn{1}{c}{$\begin{array}{c}\text { Damage cases } \\
\text { (c/h) ratio }\end{array}$} & \multicolumn{3}{c}{ Natural Frequency in $\mathrm{Hz}$} \\
Healthy beam or no & 72.56 & $2^{\text {st }}$ Mode & 391.51 \\
damage & & 199.87 & 391.50 \\
0.1 & 71.55 & 198.81 & 391.37 \\
0.2 & 71.53 & 198.80 & 391.34 \\
0.3 & 71.51 & 198.73 & 391.41 \\
0.4 & 71.47 & 198.61 & 391.42 \\
0.5 & 71.40 & 198.33 & 391.32 \\
0.6 & 71.23 & 197.69 & 391.06 \\
0.7 & 70.74 & 195.87 & 390.19 \\
0.8 & 68.82 & 189.82 & 386.26 \\
0.9 & 54.78 & 162.29 & \\
\hline
\end{tabular}

Table 2: Natural frequency values for undamaged and all damage cases.

\section{WAVELET ANALYSIS}

he modal data (displacement/ modal strain energy) from different cases of damaged beam is processed through wavelet signal processing toolbox in MATLAB software. After some experimentation it is concluded that range of scale lies between 8 to 32 showed good results for severity of damage estimation. Gaussian wavelet selected as mother wavelet transform along with four vanishing moments for processing the modal data. The wavelet transform coefficients obtained are utilized for identification of damage.

\section{Results and discussion}

Fig. 4(a) represents the plot of displacement or spatial mode shape data for undamaged or healthy beam and damaged beam model with damage level $(c / h=0.7)$ with which not able to identify the damage location. The first mode shape plot of damaged beam is transformed through Gaussian wavelet and the resulting respective wavelet coefficients values are plotted in scale value -translation plane as observed in Fig. 4(b). It is clearly observed in the three dimensional plot, which at node number 1600, highlighted with mark change in wavelet coefficients values occurs with respect to adjacent element, represents presence of damage.

Fig. 4(c) shows plot of maximum wavelet coefficients corresponding to damage location varying with scales in logarithmic axes. The data is linear fitted and the slope of line gives the Hoelder exponent and y-intercept gives the intensity factor. To simultaneously provide information on detection, localization and quantification (Level I, II and III) of damage case in a single plot the variation of Hoelder exponent is plotted with node number (along the length of the beam) as observed in Fig. 4(d).

Sudden changes of exponent value at a specific location, give information's on chance of damage presence and the less values of exponent at that location highlights the damage severity level. Greater the damage severity lower will be the Hoelder exponent value because Hoelder exponent provides the information about the estimation of regularity of the signal or data at the damaged location.

Similarly, the plots for the different damage cases c/h of 0.7, 0.5 and 0.2 are plotted in Fig. 5, 6 and 7 respectively.

It is showed that in Fig. 5(a) for mode shapes of damage case of $c / h=0.7$ corresponding to both undamaged and damaged beam cases are same or identical and locating the damage becomes difficult. When the modal data of damaged beam is processed through wavelet analysis and plotted in scale-translation plane, damage is clearly located by high value of wavelet coefficients at 1600th node location. It is seen in Fig. 5 (d) which gives damage level in terms of Hoelder exponent value, minimum value of exponent at the damaged location has increased when compared to the previous case of $\mathrm{c} / \mathrm{h}$ 0.9. This concludes that this method has accurately measured the severity of damage exponent in the sense that as damage decreases the regularity in the signal at damage increases, hence the Hoelder exponent increases. 


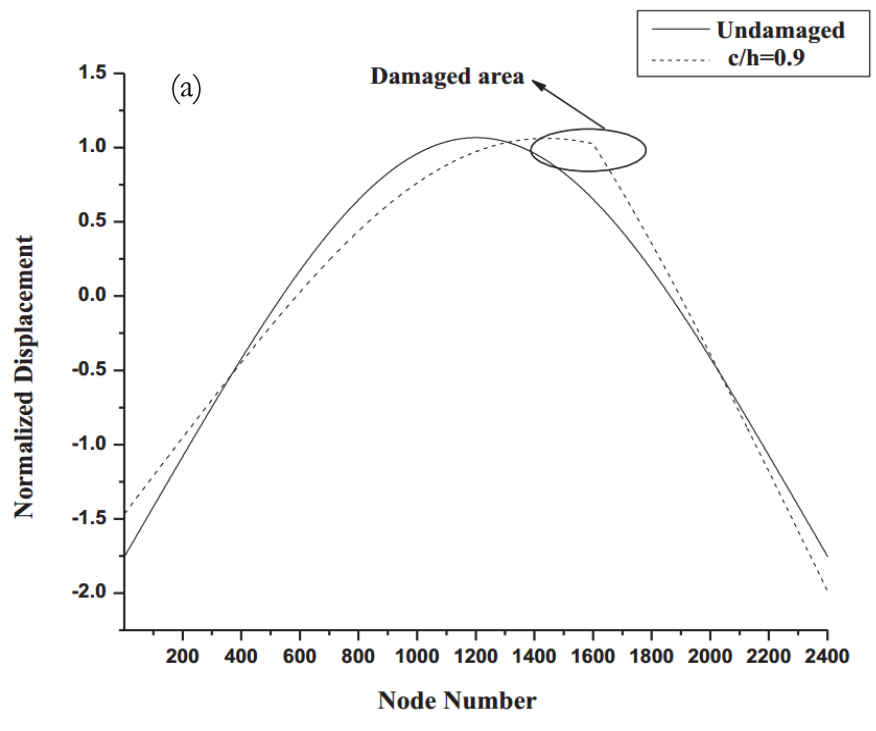

(a) First fundamental mode shape data plot

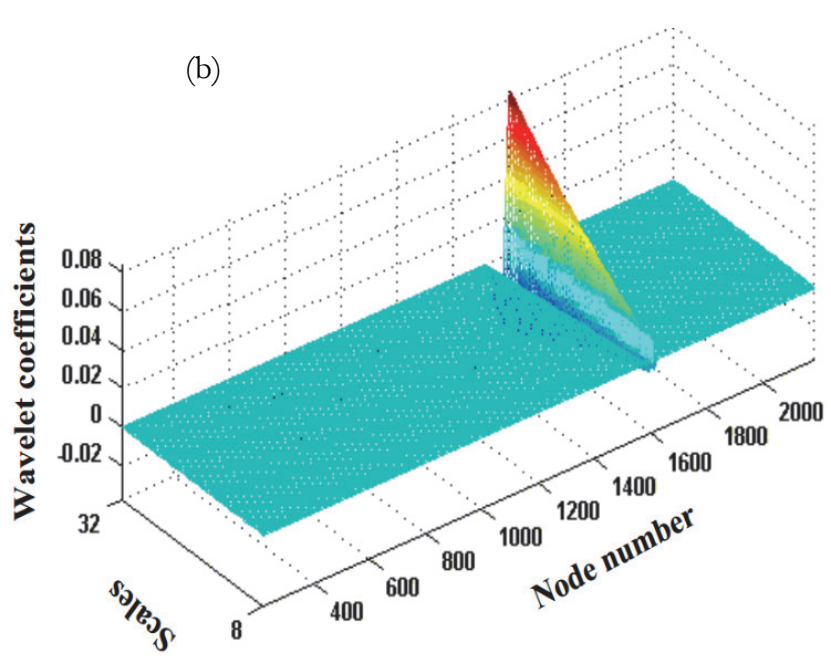

(b) Three dimensional wavelets plot in Scale-translation plane

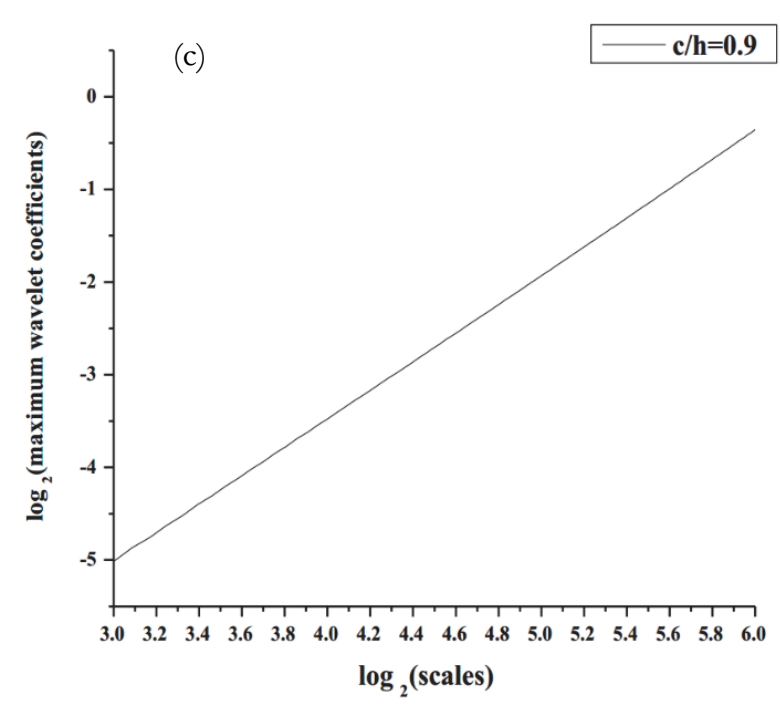

(c) Maximum Modulus line at 1600th node (d)

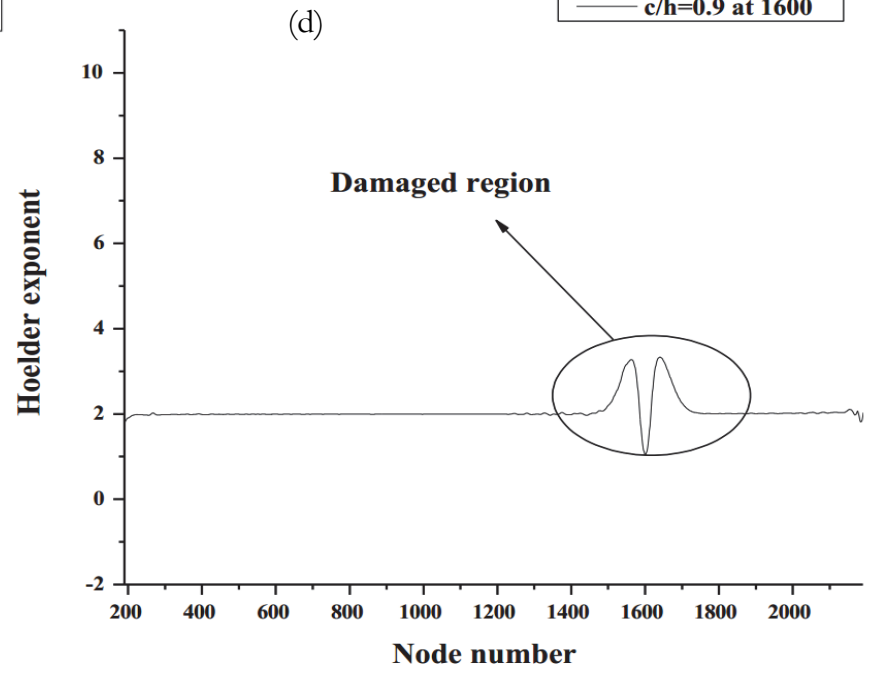

(d) Hoelder exponent for damaged beam.

Figure 4: Damage identification for damage case as $\mathrm{c} / \mathrm{h}=0.9$ 


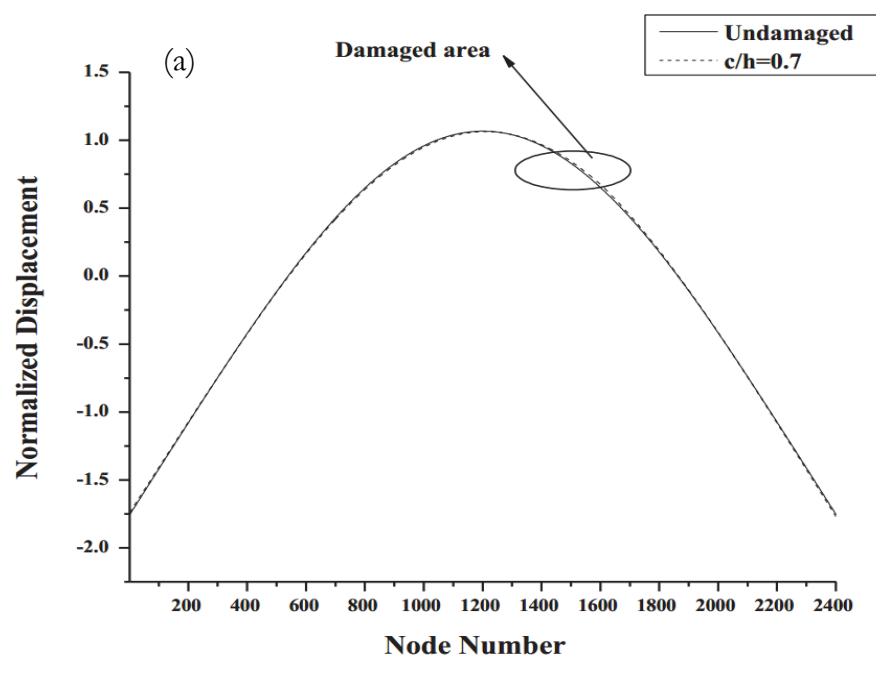

(a) First fundamental mode shape data plot

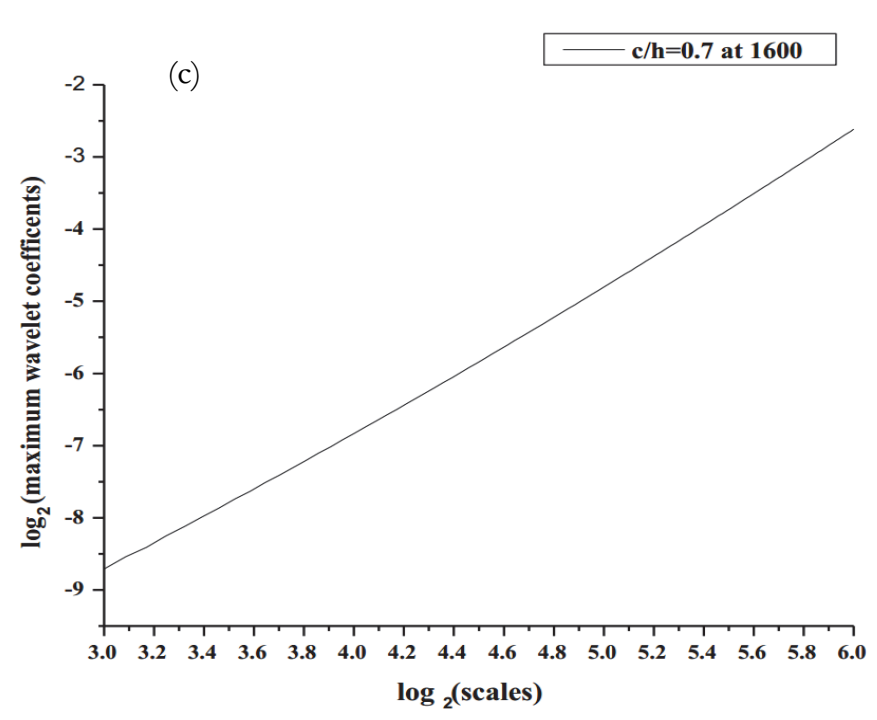

(c) Maximum Modulus line at 1600th node (b)

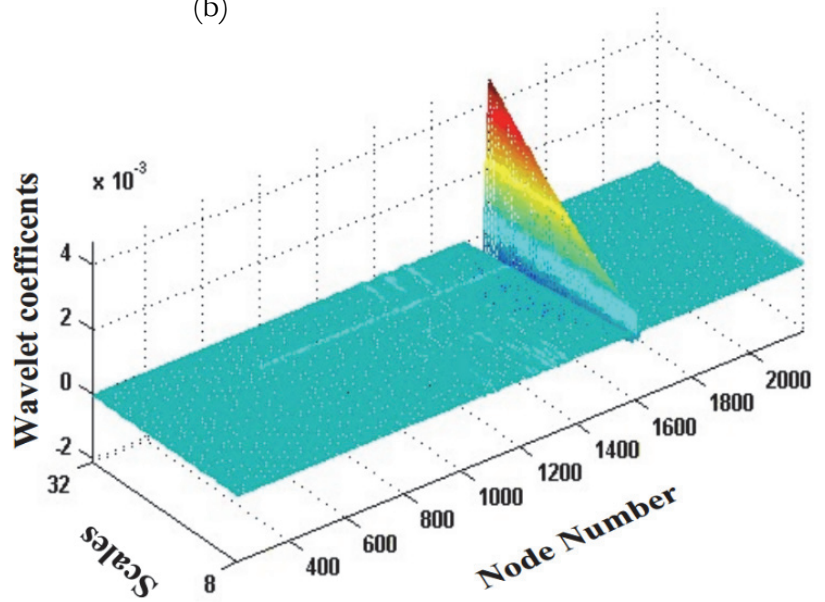

(b) Three dimensional wavelet plot in Scale values-translation plane

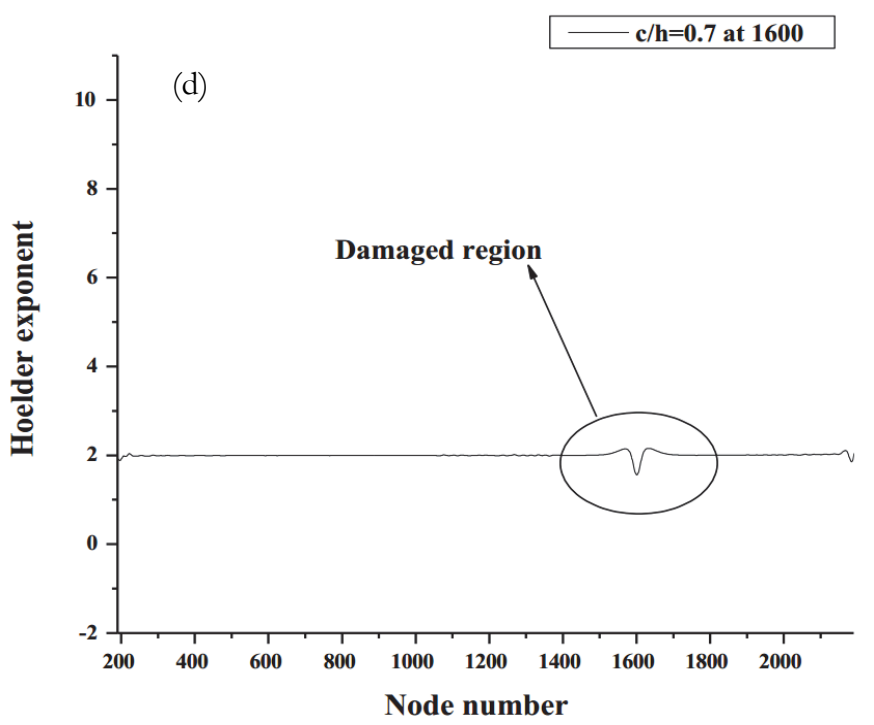

(d) Hoelder exponent plot along the beam length.

Figure 5: Damage identification for damage case i.e. $\mathrm{c} / \mathrm{h}=0.7$

By observing Fig. 6(d) which is three dimensional wavelet coefficient graphs for damage of $\mathrm{c} / \mathrm{h}$ 0.5, it is observed that there are some minor peaks at the middle of the beam. This may be attributed to the relative curvature profile variation in mode shape at the middle with respect to curvature at damage region. 

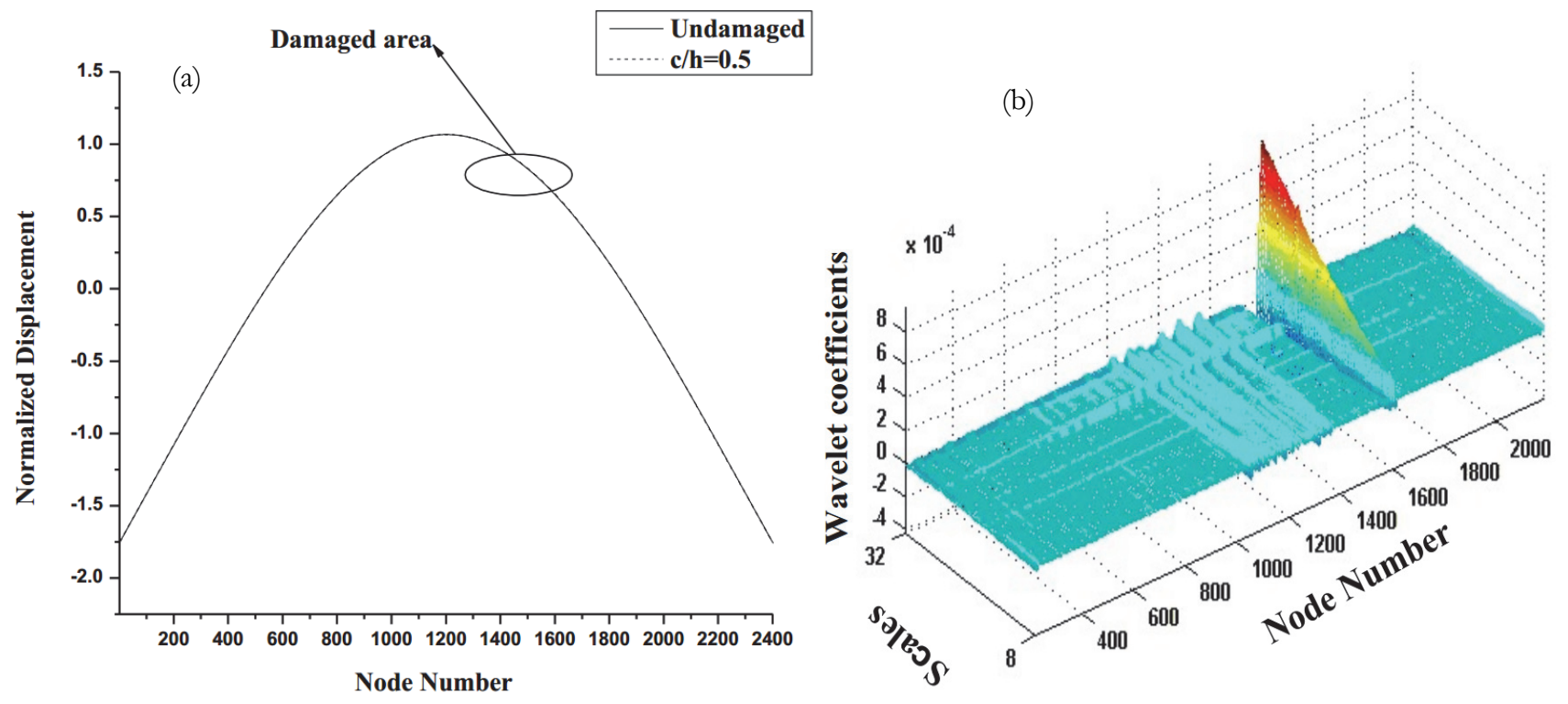

(a) First fundamental mode shape data plot

(b) Three dimensional wavelet plot in Scale value -translation plane

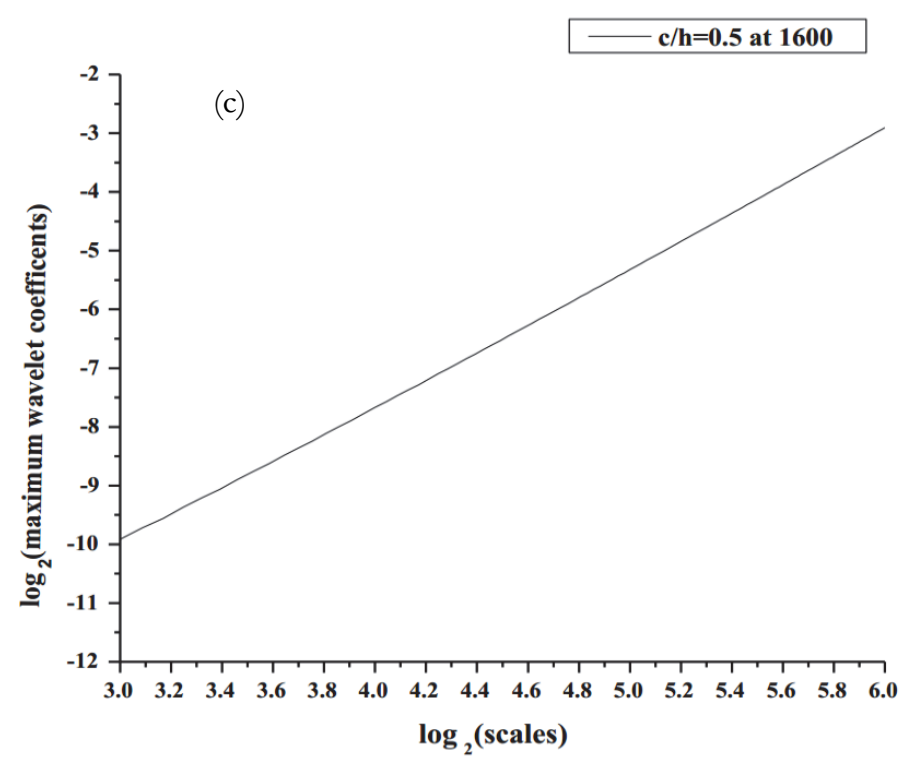

(c) Maximum Modulus line at 1600 node

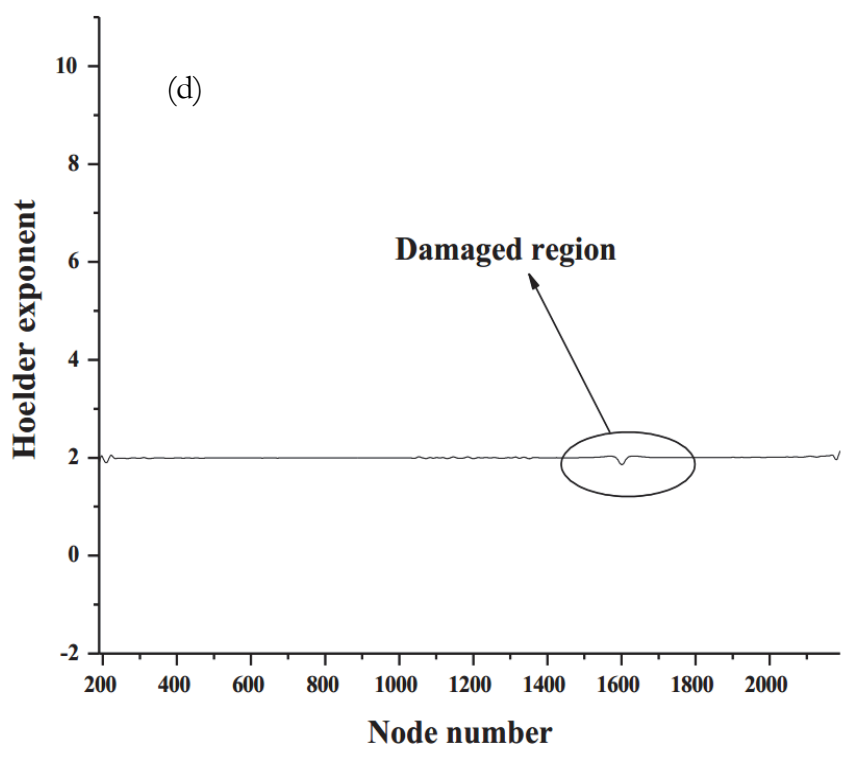

(d) Hoelder exponent plot along the beam length.

Figure 6: Damage identification in case of single location damage i.e. $\mathrm{c} / \mathrm{h}=0.5$ 


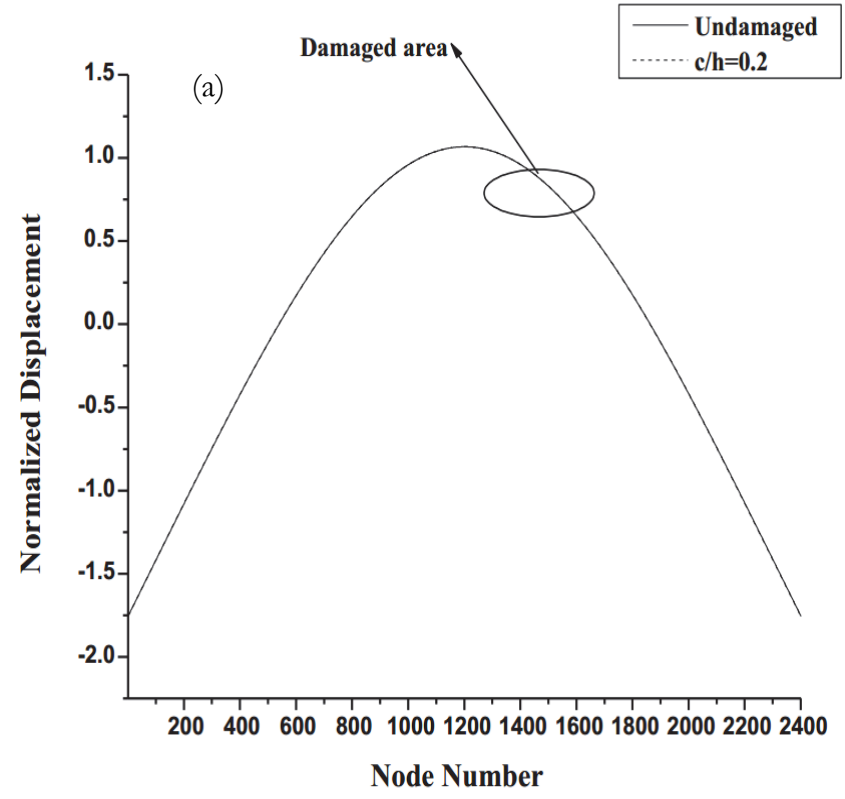

(a) First displacement mode shape

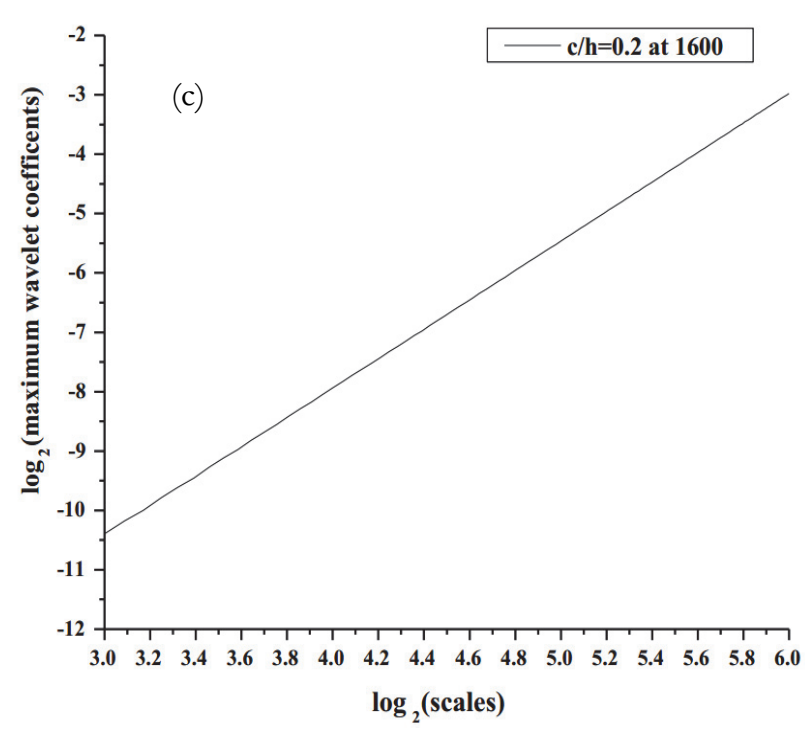

(c) Maximum Modulus line at 1600 node

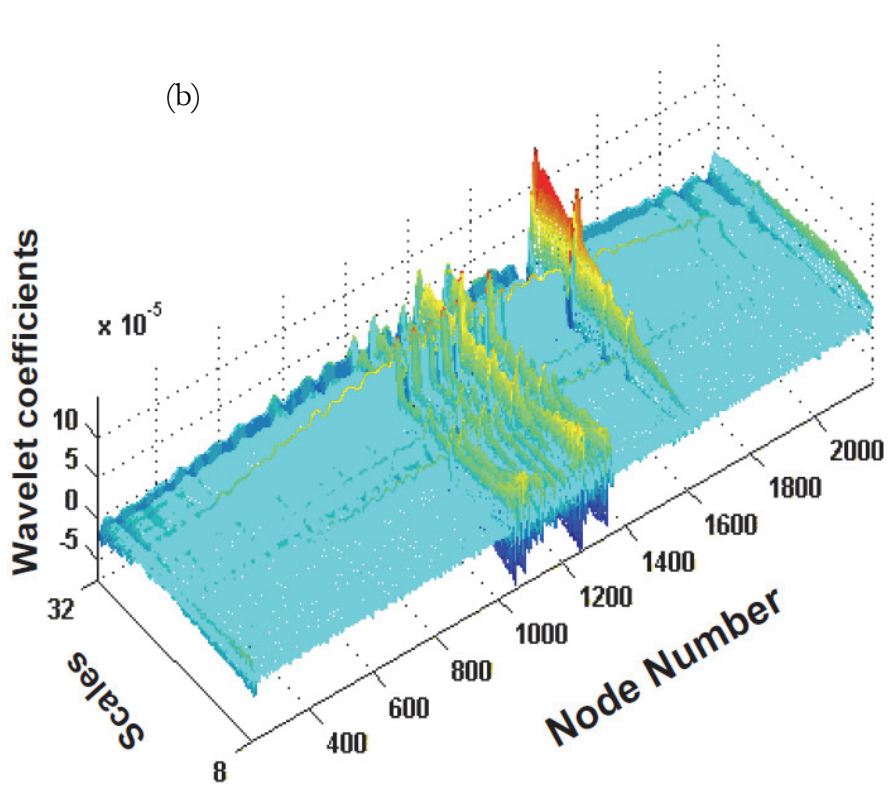

(b) Three dimensional wavelet plot in Scale-translation plane

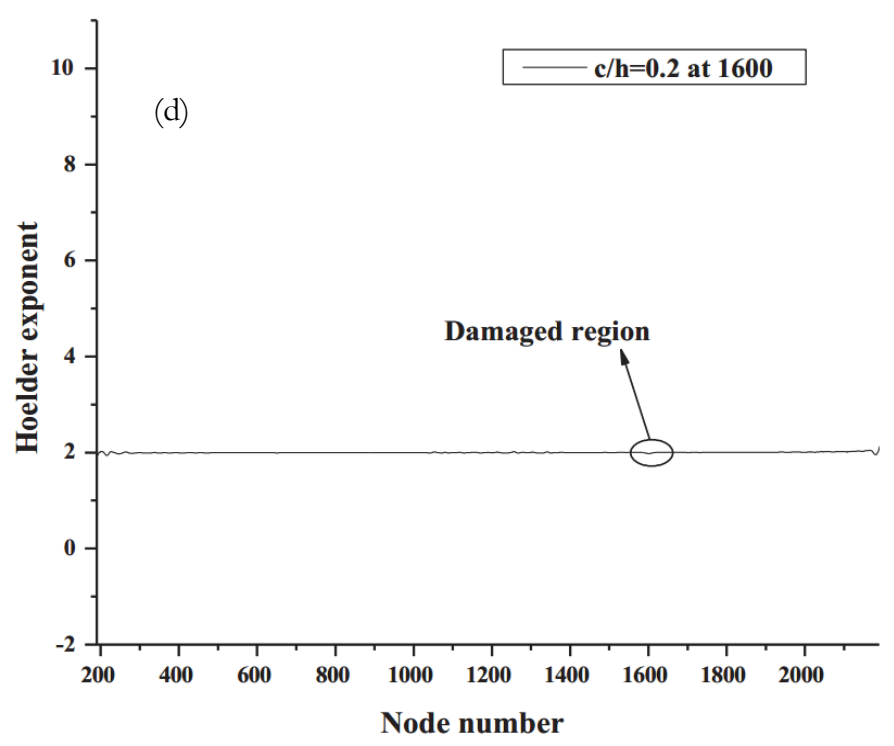

(d) Hoelder exponent plot along the beam length.

Figure 7: Damage identification for damage case i.e. $\mathrm{c} / \mathrm{h}=0.2$

Fig. 7 (b) highlights the three dimensional wavelet coefficients plot for damage case $\mathrm{c} / \mathrm{h}=0.2$ which gives small peak with less value of wavelet coefficients at damaged location.

To be consistent with the concept of increasing damage sensitive parameter with increasing damage extent, the Hoelder exponent at damaged location is subtracted from value of exponent at undamaged location i.e., 2 which is called as Damage index based on Hoelder exponent.

Damage index $=2-$ Hoelder Exponent at damaged element Intensity factor $=2$ (v-intercept) 

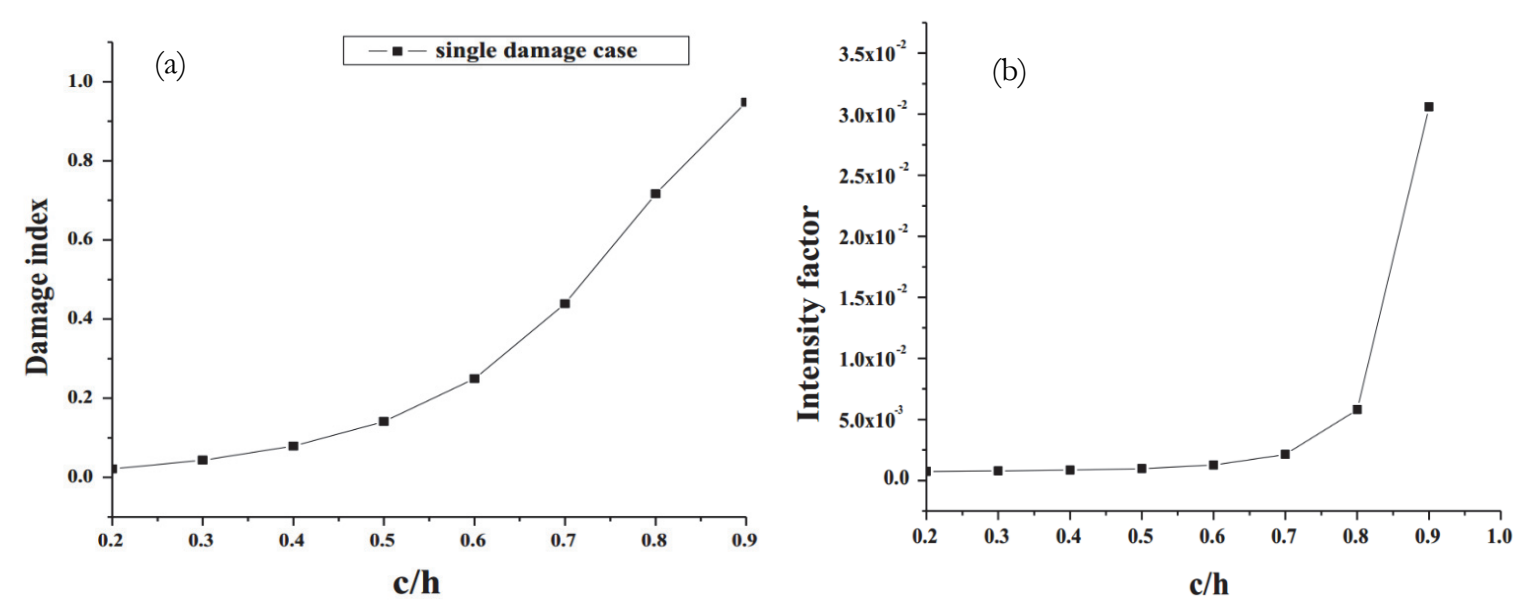

(a) Damage index for all damage cases $(\mathrm{c} / \mathrm{h}=0.2$ to 0.9$)$ (b) Intensity factor value for all damage cases (c/h $=0.2$ to 0.9$)$.

Figure 8: Damage quantification for single location damage

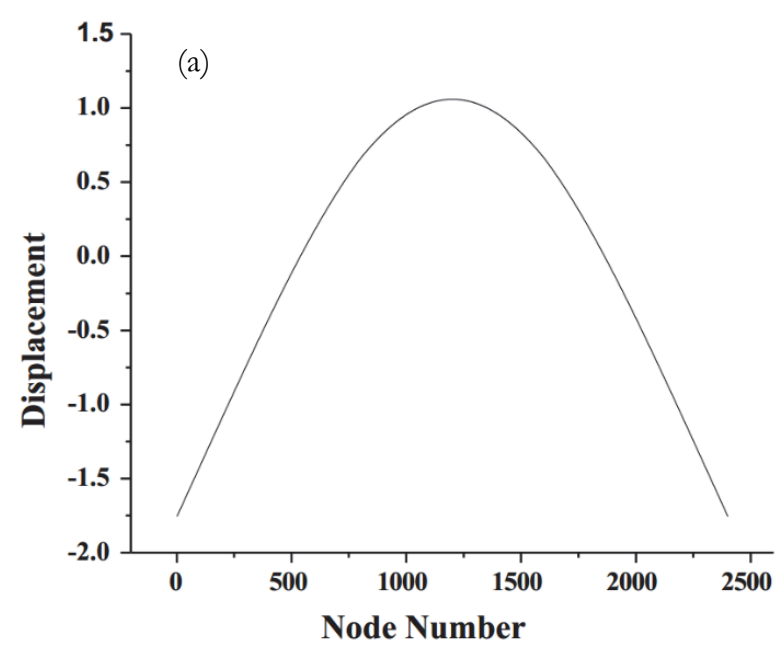

(a) First displacement mode shape

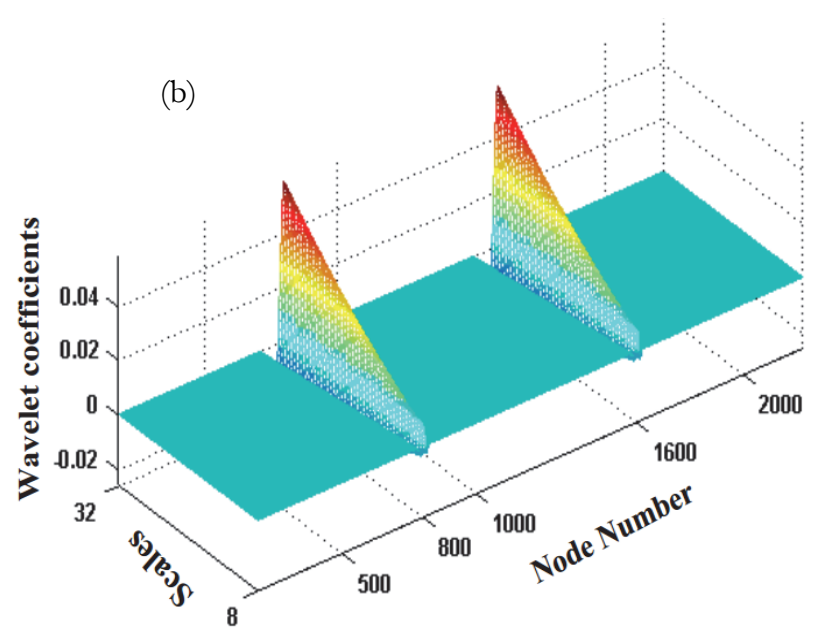

(b) Three dimensional wavelet plot in Scale value-translation plane

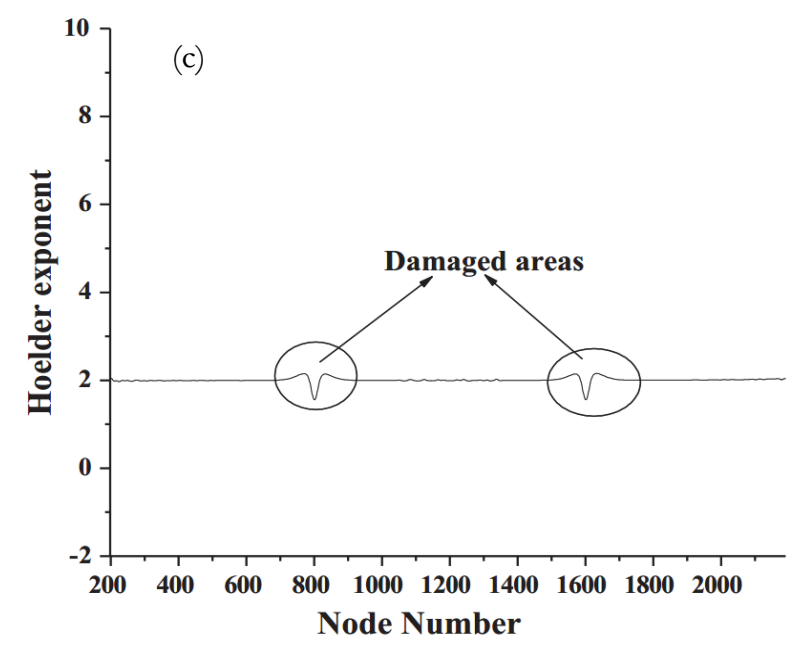

(c) Hoelder exponent plot along the beam length.

Figure 9: Damage detection in case of double location damage for $\mathrm{c} / \mathrm{h}=0.7$ 
As damage severity increases, Hoelder exponent value (which gives the order of regularity) at the damaged place decreases, thereby the index of damage increases as observed in Fig. 8 (a). The intensity factor increases with increasing damage as in Fig. 8 (b). It is also observed that the damage index with respect to Hoelder exponent is highly sensitive to damage compared to Intensity Factor and therefore can be used as better damage indicator.

\section{Damage detection with multiple structural damages}

To inspect the success of the wavelet-based method to identify the multiple structural damages by using the modal signal or shape of same damaged beam and multiple damages are modelled at 800 and $1600^{\text {th }}$ elements. From Fig. 9 (a) highlights the first mode shape of damaged beam with damaged case $c / h=0.7$ at 800 and $1600^{\text {th }}$ elements.

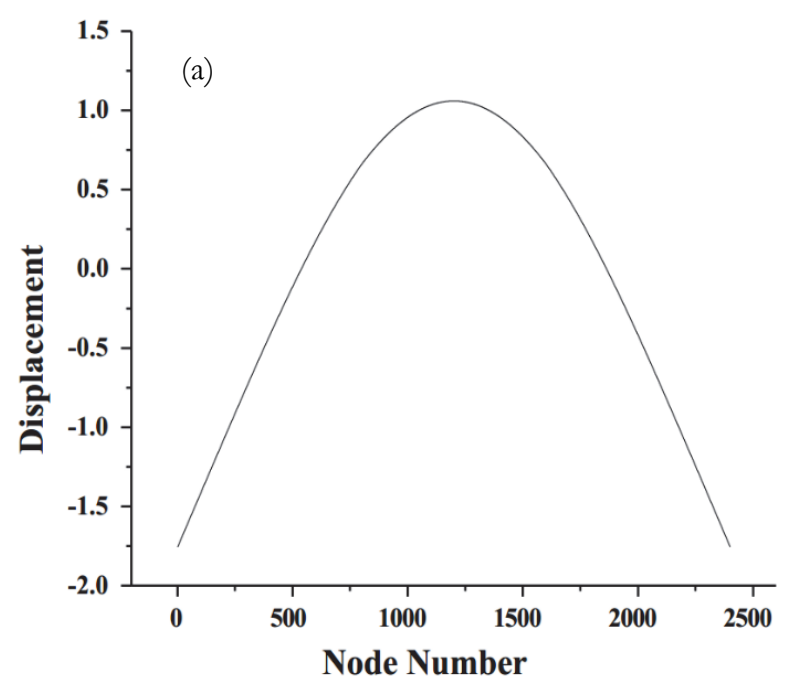

(a) First displacement mode shape

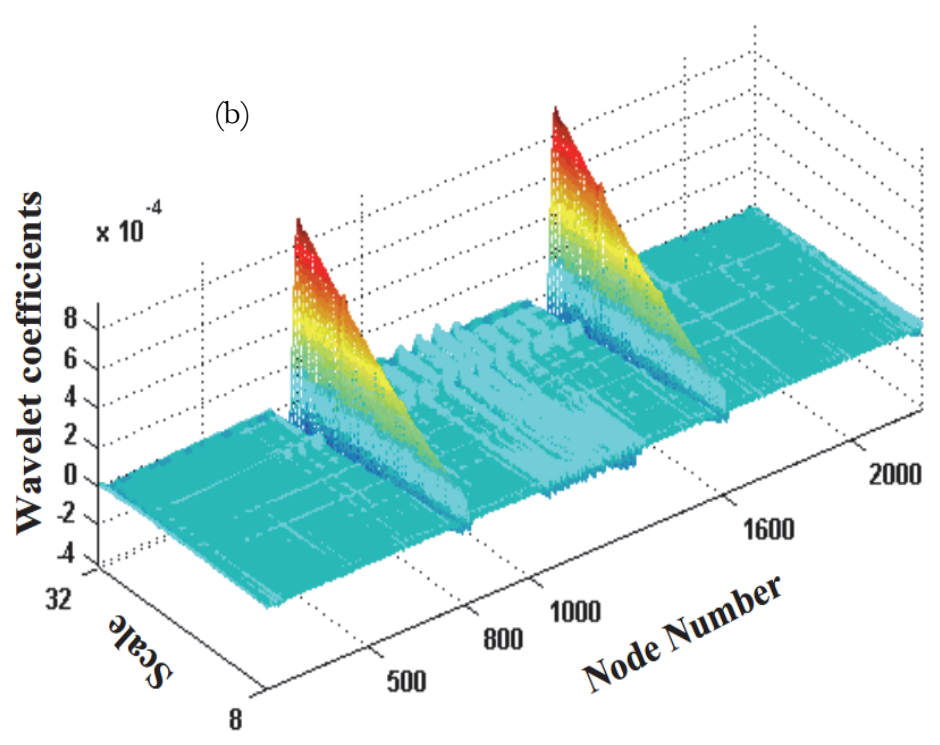

(b) Three dimensional wavelets plot in Scale value-translation plane

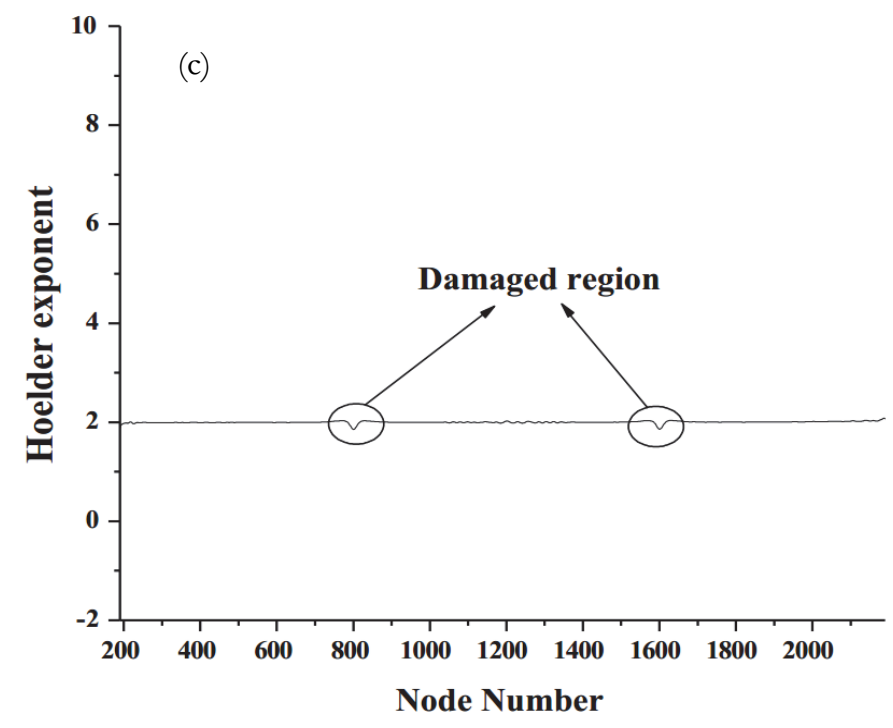

(c) Hoelder exponent plot along the beam length.

Figure 10: Damage identification in case of double location damage for $\mathrm{c} / \mathrm{h}=0.5$ 


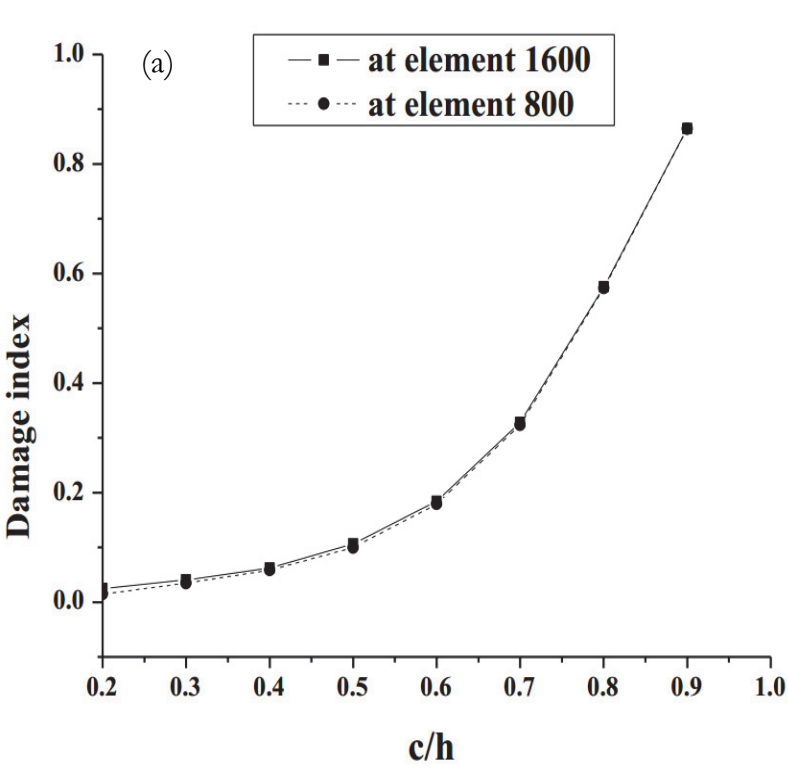

(a) Damage index for all damage cases

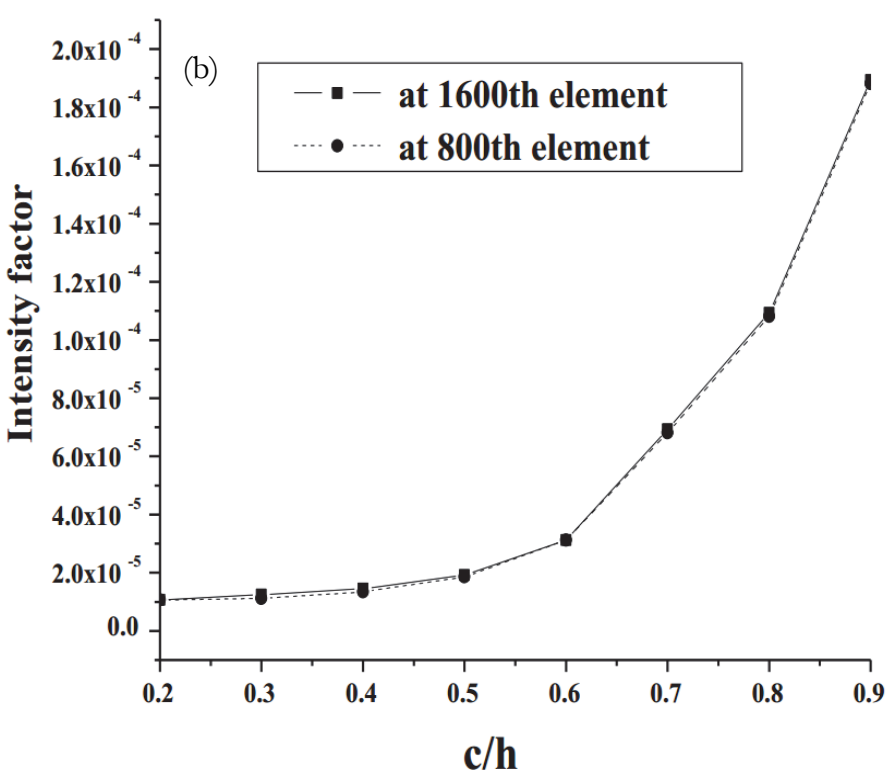

(b) Plot of Intensity factor for all damage cases

Figure 11: Damage quantification for double location damage

Damage quantification for multiple damages at 800 and $1600^{\text {th }}$ nodal points showed in Fig. 11. It is also observed that the values of the intensity factor and damage index are same behavior for both damages and they increase with damage severity in $\mathrm{c} / \mathrm{h}$. The damage index parameter is highly sensitive to damage compared to Intensity Factor. Comparing Figs. 11(a) and 11(b), it is seen that the intensity factor becomes more sensitive to dual damage (Fig. 11 (b)) compared to single damage Fig. 8 (b).

\section{Modal strain energy data to improve the sensitivity of damage detection}

It is observed that method of using modal or spatial data to identify damage is not sensitive to damage severity with $\mathrm{c} / \mathrm{h}=0.2$ and below. Fig. 12 highlights three dimensional wavelet plot for damage $\mathrm{c} / \mathrm{h}=0.1$, where it is not possible to locate the damage point by observing high wavelet coefficients at damage points. The effectiveness of the smaller damage cases $(\mathbf{c} / \mathbf{h}=\mathbf{0 . 1})$ using modal strain energy values as input signal to wavelet process is explored. It is already showed that modal strain energy data is high sensitive to damage identification compare to the mode shape data Stubbs et al. [5]. Processing the modal strain energy data through wavelet transform results in high sensitive for very small level of damage identification.

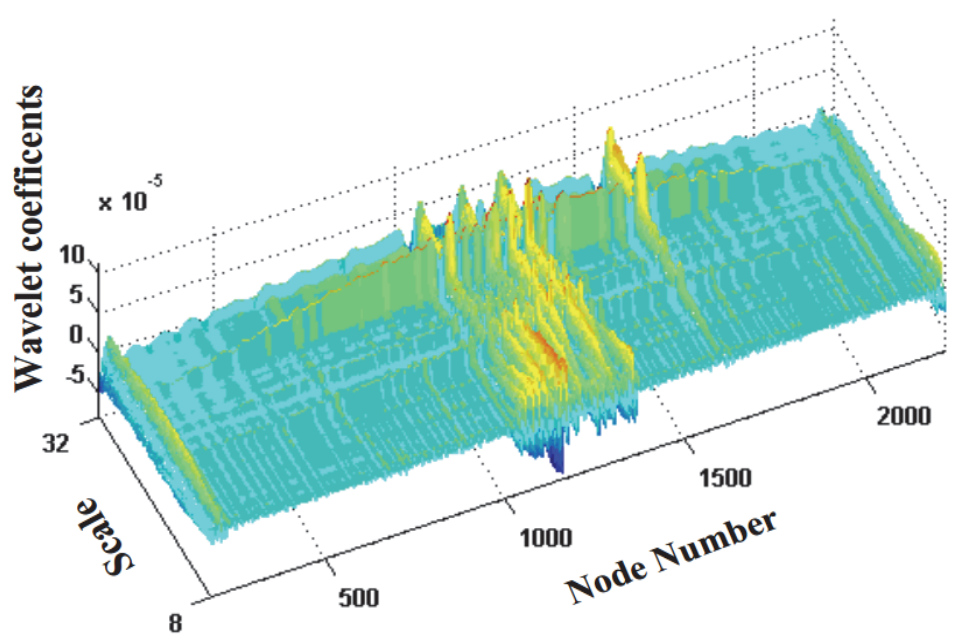

Figure 12: Three dimensional wavelet plot using modal or spatial mode shape for damage case $\mathrm{c} / \mathrm{h}=0.1$ 


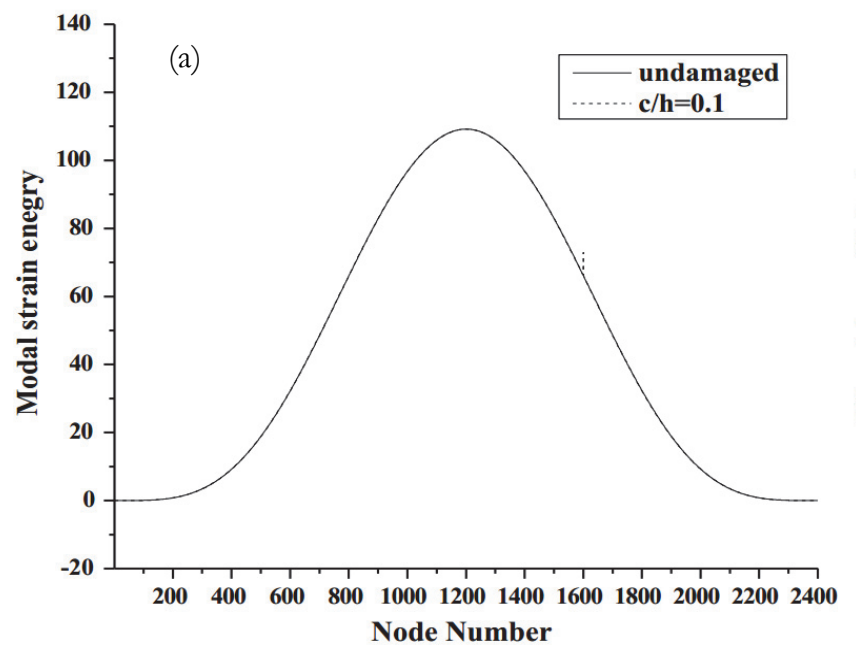

(a) First modal strain energy data plot

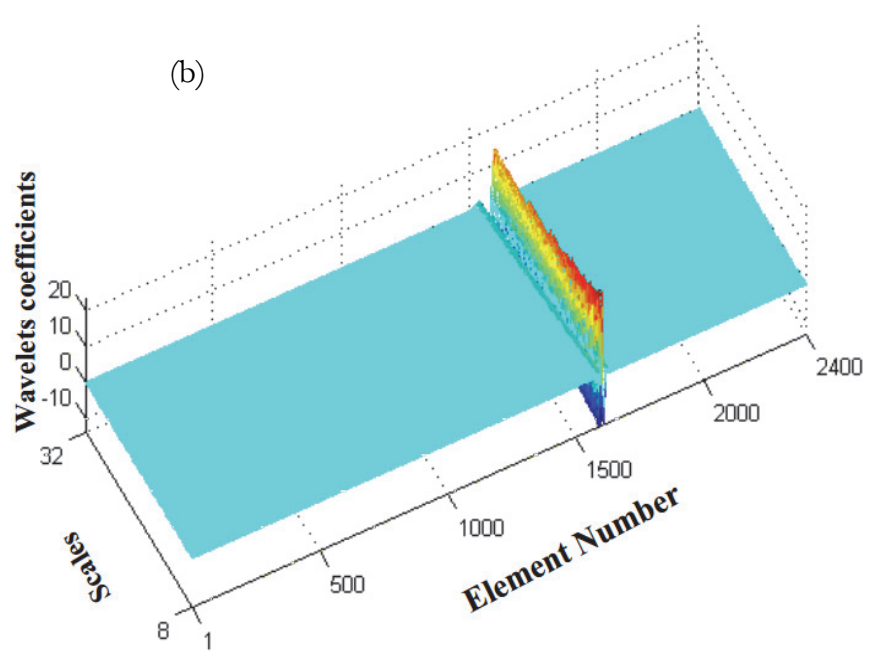

(b) Three dimensional wavelet plot

Figure 13: Damage detection using wavelet and modal strain energy data for damage case for $\mathrm{c} / \mathrm{h}=0.1$

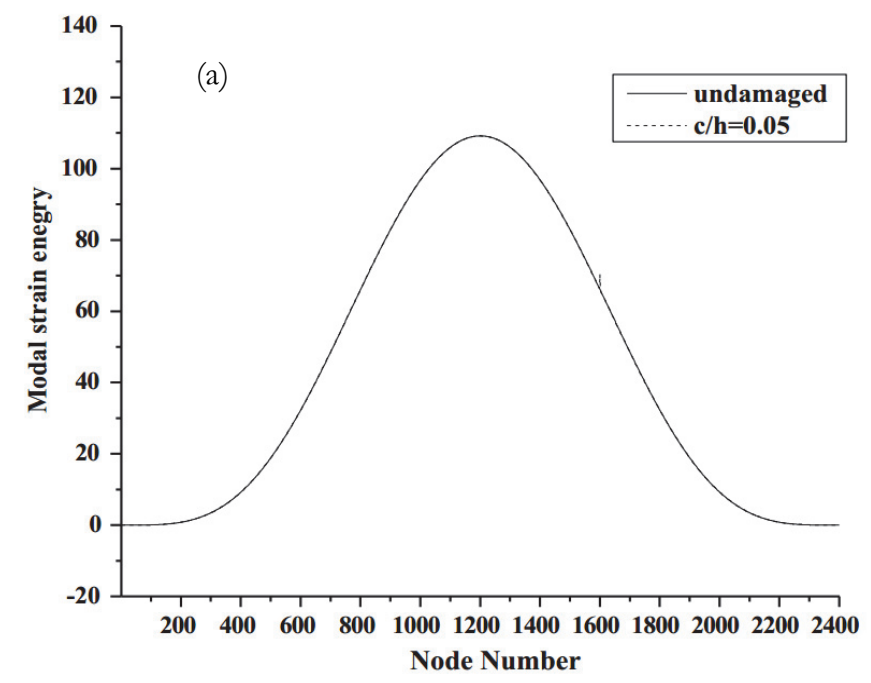

(a) Plot of first modal strain energy data

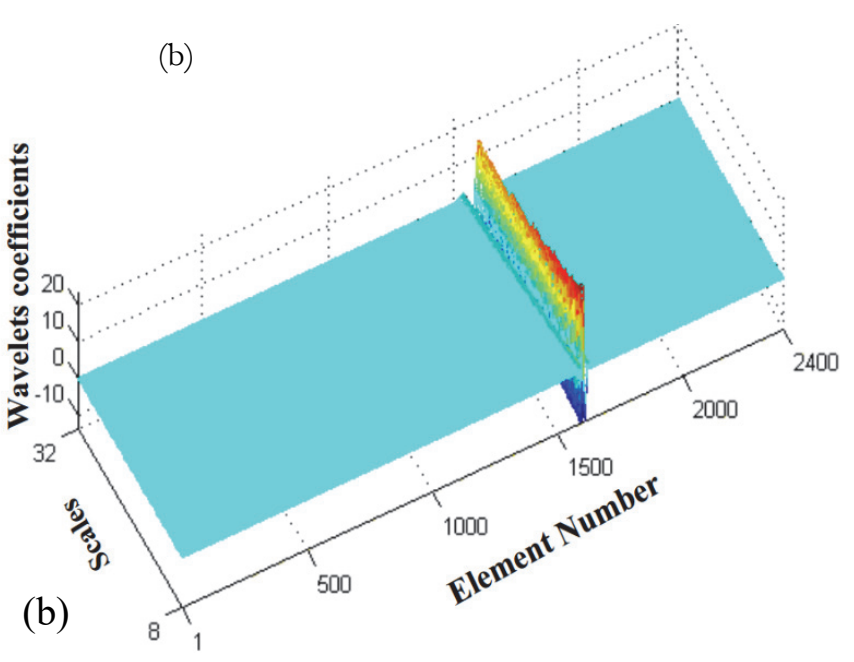

(b) Three dimensional wavelet processed plot

Figure 14: Damage detection using wavelet and modal strain energy data for damage $\mathrm{c} / \mathrm{h}=0.05$

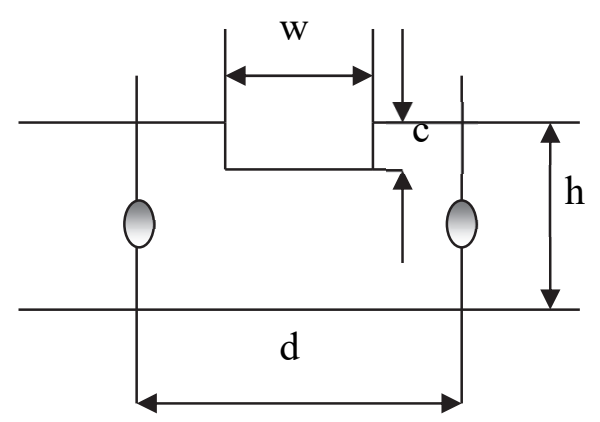

Figure 15: Damage geometry showing spatial sampling 


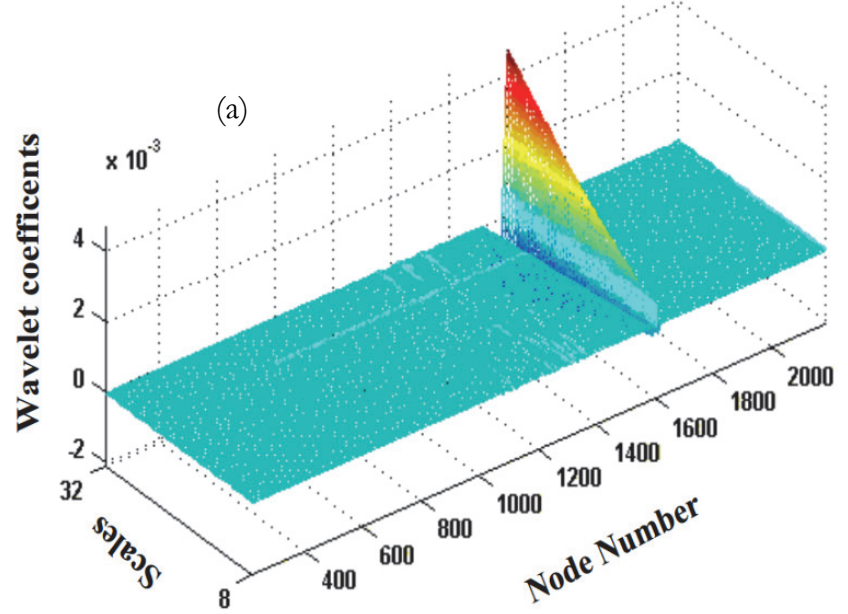

(a) $\mathrm{w} / \mathrm{d}=1$

(c)

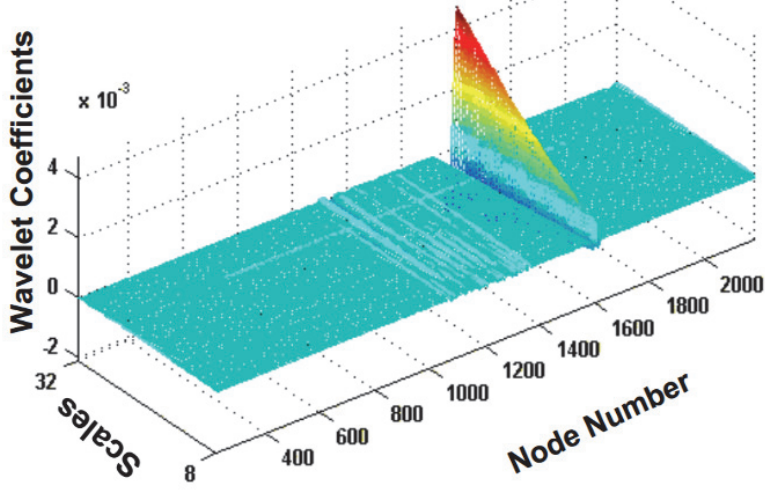

(c) $\mathrm{w} / \mathrm{d}=1 / 4$

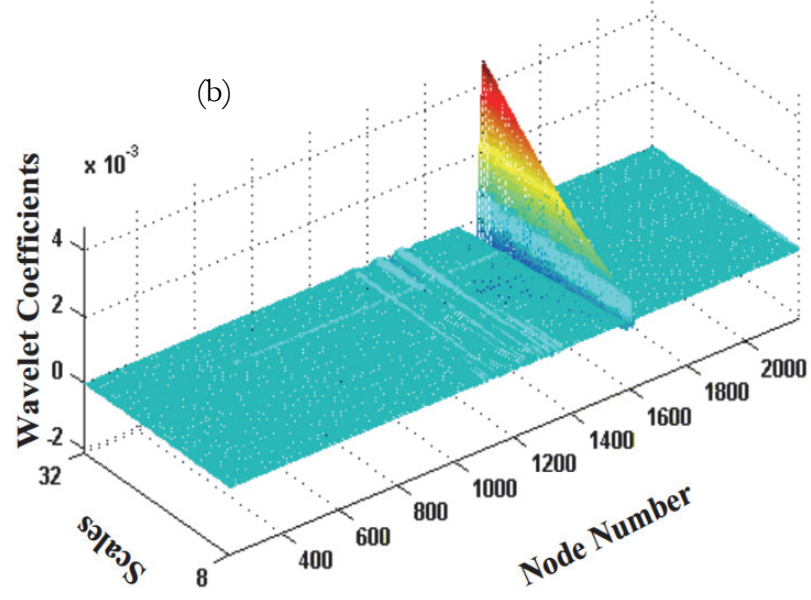

(b) $w / d=1 / 2$

(d)

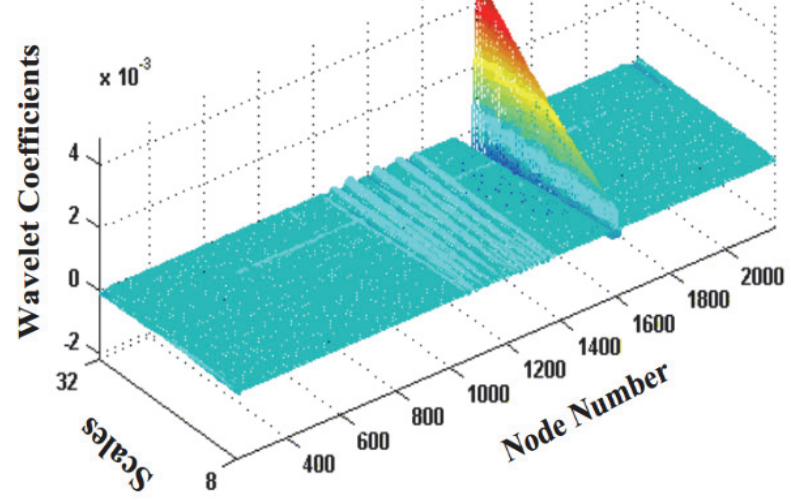

(d) $w / d=1 / 10$

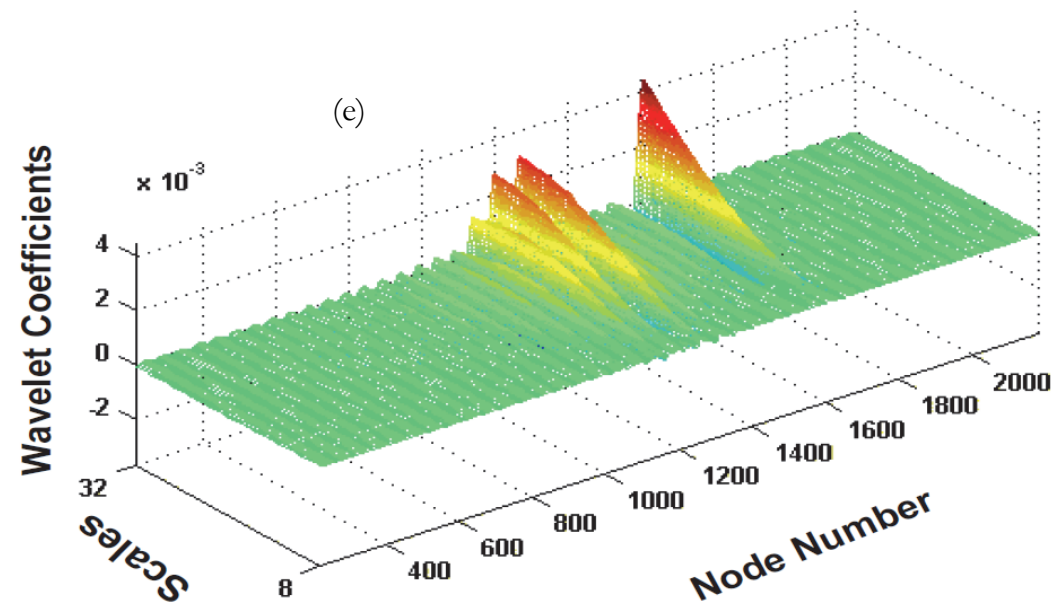

(e) $\mathrm{w} / \mathrm{d}=1 / 50$

Figure 16: Effect of reduced spatial sampling on damage localization for $\mathrm{c} / \mathrm{h}=0.7$. 
Fig. 13 (a) highlights the first fundamental modal strain energy data for damage $\mathrm{c} / \mathrm{h}=0.1$, in which the damage location detected with clear peak at $1600^{\text {th }}$ node this node number denotes element also because 1600 element shares 1600 and 1601 nodal points. Wavelet processed modal stain energy signal or data is plotted in scale value -element number plane Fig. 13(b), highlights the changes of wavelet coefficients near the damage location, which assistances in identifying the damage location and severity. Fig. 14 highlights the superiority of this method of using modal strain energy for identification of smallest level of damage case (crack size) $\mathrm{c} / \mathrm{h}$ is 0.05 .

\section{Effects of Spatial sampling on damage localization}

Spatial sampling points are actual sensing points. Considering experimental modal analysis, it is required to estimate minimum spatial sampling points as necessary for damage detection with respect to a chosen model of damage.

Spatial Sampling is defined by w/d, where 'w' represents the width of damage and ' $d$ ' is spatial sampling distance as shown in Fig. 15. The damage identification is strongly dependent on the spatial sampling. Previously, the analysis is done with 2401 spatial points i.e., sampling at each node $(\mathrm{w} / \mathrm{d}=1)$. Now, the analysis is carried out for reduced spatial sampling of $\mathrm{w} / \mathrm{d}=1 / 2$ (1201 spatial points), 1/4 (601 spatial points), 1/10 (241 spatial points), 1/50 (49 spatial points).

The sampled spatial signal is cubic spline interpolated (Shape preserving interpolation function in MATLAB) to obtain 2401 points which is same as the original spatial sampling at each node.

The results of wavelet coefficients as a function of scales and node number are shown for the two damage cases of $\mathrm{c} / \mathrm{h} 0.7$ and 0.5 are highlighted in Fig. 16 and Fig. 18 respectively. The method correctly identifies the damage by high wavelet coefficients at single location (1600 spatial point) up to sampling of $w / d=1 / 10$. But for case less than sampling of $1 / 50$ (49 points) there are certain locations other than damage location marked by high wavelet coefficients as shown in Fig. 16 (e). This is generally the case when using experimental obtained spatial data where there are minimum spatial sampling points.

This problem in identifying damage can be solved by careful examination of the decay behavior of maximum wavelet coefficients with decreasing scales. Angrisani et al. [8] showed that for a typical damage to exist, absolute maximum wavelet coefficients should decrease for decreasing scales in a regular manner as shown in Fig. 17 (a).

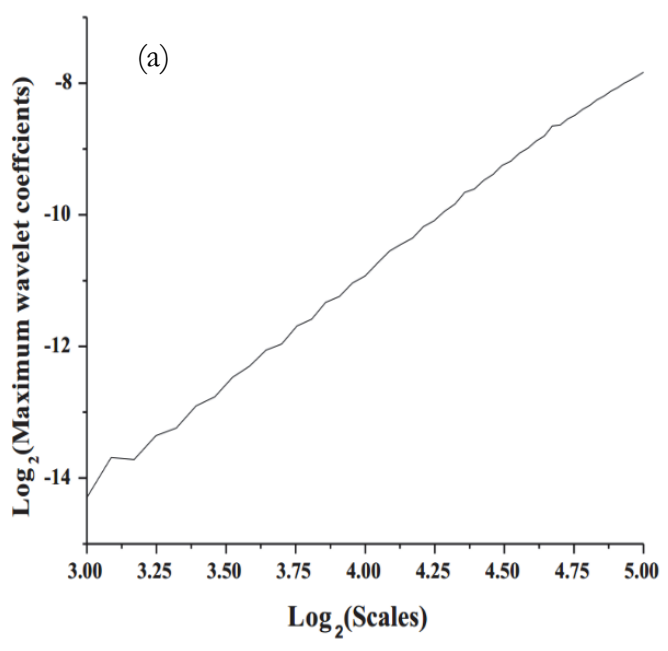

(a) Node number 1600 (damaged location)

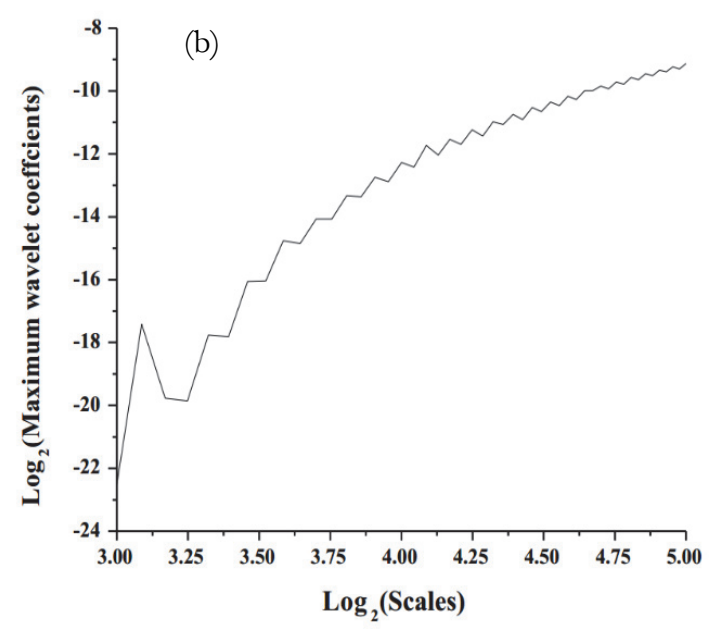

(b) Node number 1275(damaged location)

Figure 17: Variation of Maximum wavelet coefficients with wavelet scales for $\mathrm{c} / \mathrm{h}=0.7$

Such plots are drawn for all the points of high wavelet coefficients on the 3-D plots, and the damage is identified at those points where the variation is linear.

Fig. 17 (b) shows the same plot at node number 1275 where the variation is not regular, which gives false indication of damage, Fig. 18 shows similar plots for $\mathrm{c} / \mathrm{h}=0.5$. Again, it is observed that there are extra peaks other than at actual damaged location as seen in Fig. 18 (e). The behavior of maximum wavelet coefficients for decreasing scale is regular at damaged location as shown in Fig. 19 (a), indicating damage at 1600th node number. By examining the behavior of maximum wavelet 
coefficients at node number 1275 (Fig. 19 (b)) it is evident that it is false indication of damage. Fig. 20(a) and Fig. 20(b) shows the variation of intensity factor and damage index respectively for different spatial sampling. For a particular spatial sampling the value of damage index and intensity factor increases with increase in damage severity.

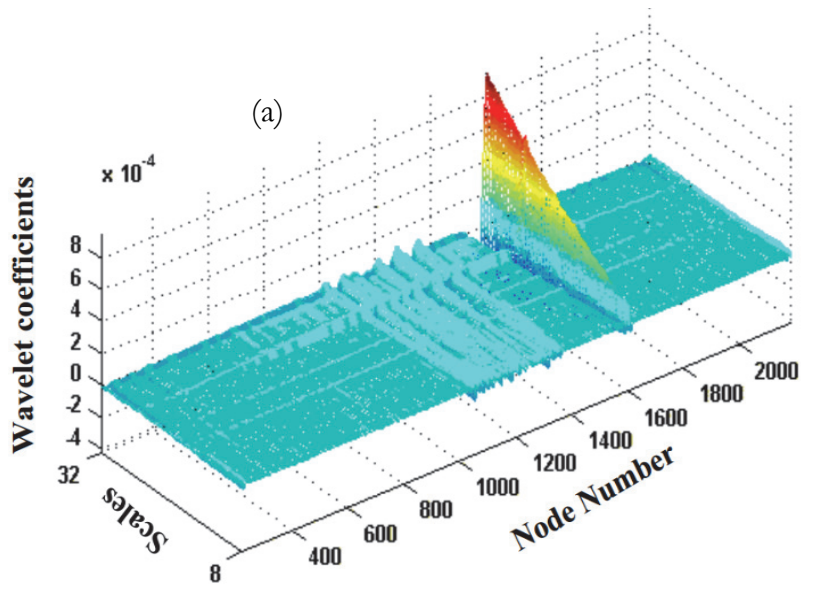

(a) $w / d=1$

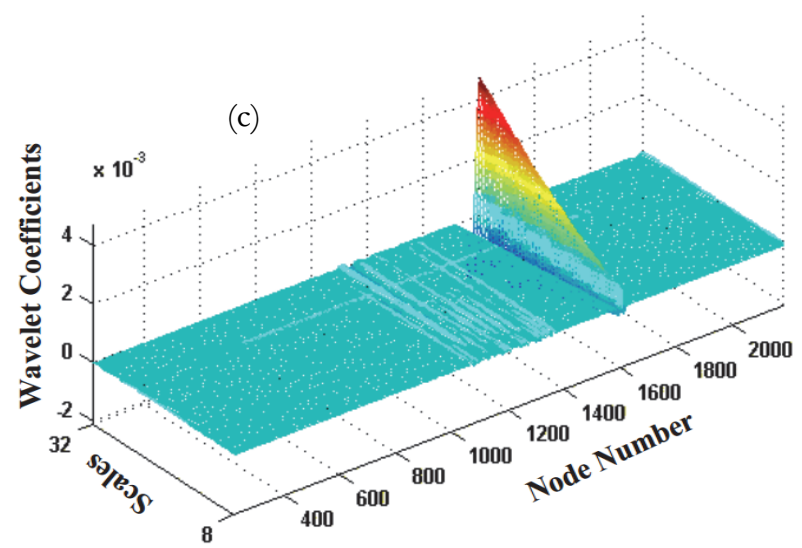

(c) $\mathrm{w} / \mathrm{d}=1 / 4$ (b)

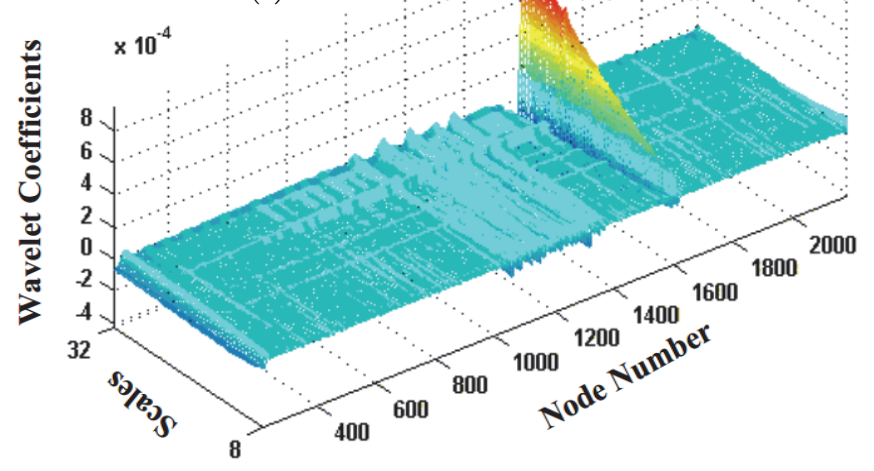

(b) $w / d=1 / 2$

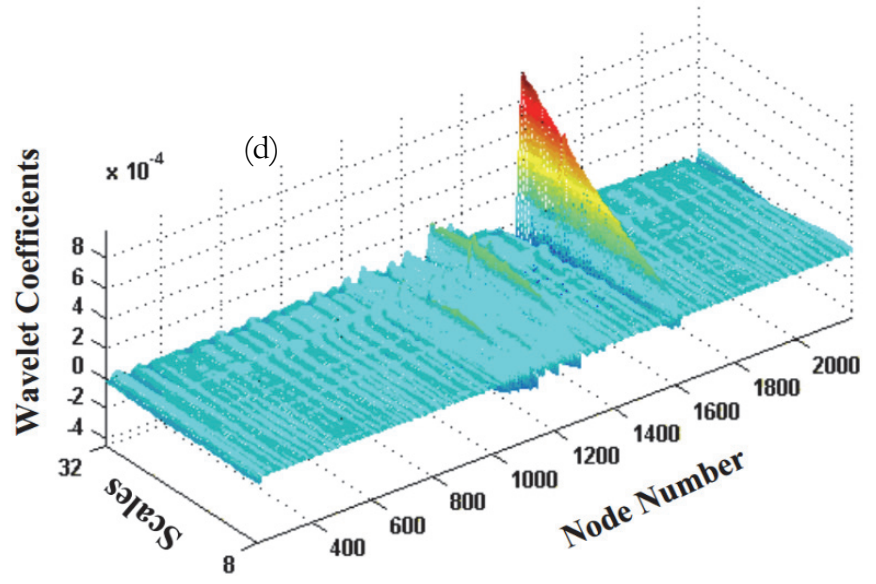

(d) $w / d=1 / 10$

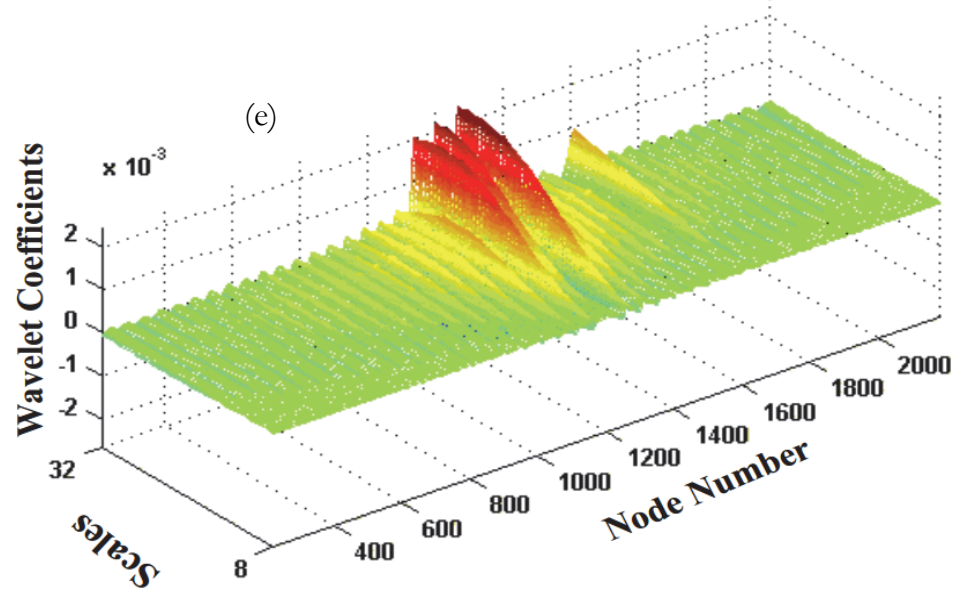

(e) $\mathrm{w} / \mathrm{d}=1 / 50$

Figure 18: Effect of reduced spatial sampling on damage localization for $\mathrm{c} / \mathrm{h} 0.5$ 
It is observed that damage index based on Hoelder exponent reduces as number sampling point is reduced as shown in Fig. 20 (a). This indicates that the singularity obtained by the damage presence to be smoothen as the result of reduced sampling points if prediction is based on the using the Hoelder exponent.

But it is observed in Fig. 20 (b) that the intensity factor increases as the number of spatial sampling points are reduced for a given damage severity $(\mathrm{c} / \mathrm{h})$. This indicates that the singularity generated by the damage appear to be larger (overestimated) than the actual as the result of reduced sampling points if prediction is based on the using the intensity factor.

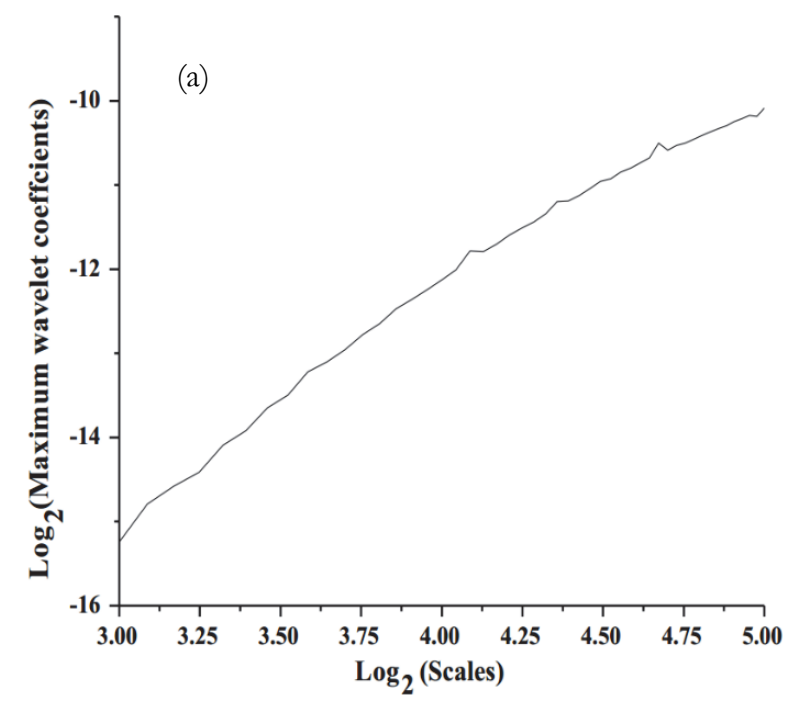

(a) Node number 1600 (damaged location)

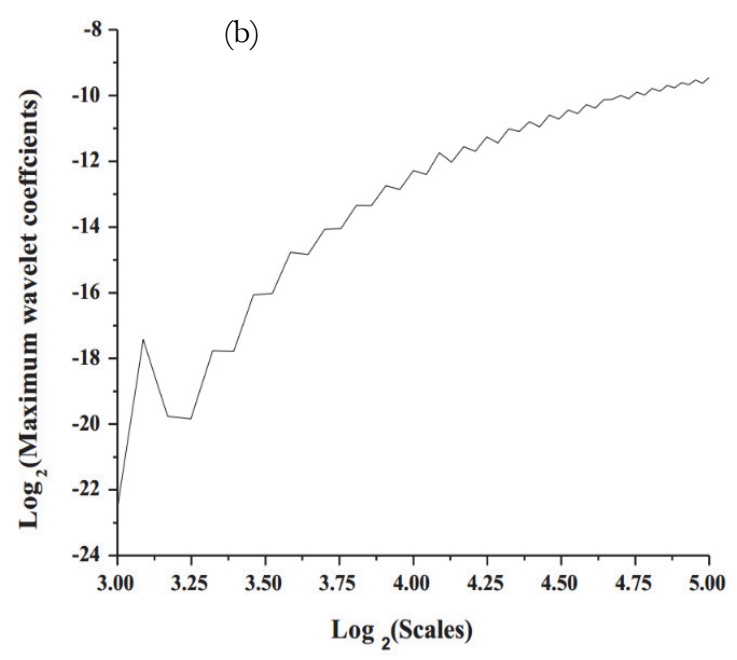

(b) Node number 1275.

Figure 19: Variation of Maximum wavelet coefficients with wavelet scales for $\mathrm{c} / \mathrm{h}=0.5$

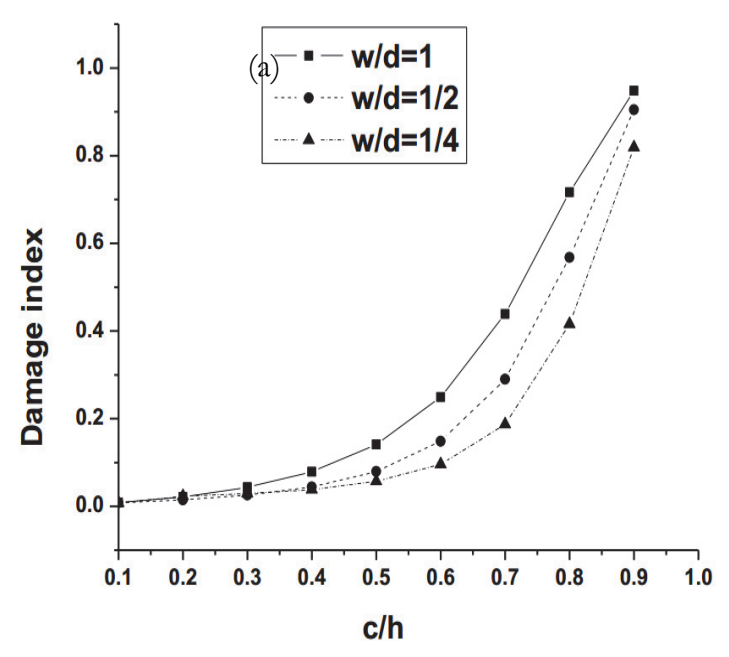

(a) Damage index

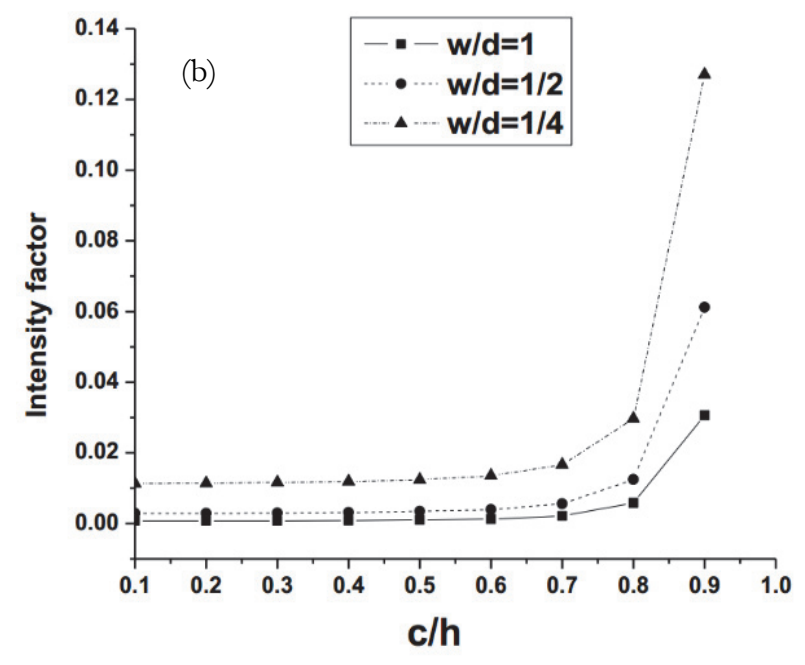

(b) Intensity Factor

Figure 20: Effect of reduced spatial sampling on damage quantification

\section{CONCLUSION}

he present work includes the study of existing damage detection based on using only the modal or spatial data and development of damage identification using wavelet transform. The three dimensional wavelets plot combined with the two dimensional Hoelder exponent plot having potential to locate the damage position (single \& multiple damages). 
1. It is showed that difference data utilized that is variation data between damaged and undamaged structure, this input processed through wavelet transform are capable to locate damage locations (single or multiple damages) clearly.

2. Hoelder exponent and intensity factor derived from wavelet coefficients quantitatively explain damage levels down to $1200 \mathrm{~mm}$ length segment divided to 2400 elements so each element is $0.5 \mathrm{~mm}, \mathrm{c} / \mathrm{h}=0.2$ means even the damage severity (depth) is $4 \mathrm{~mm}$ also this method effective.

3. Optimum spatial sampling is one of the important factors. Too high spatial sampling points are impractical because of minimum sensor availability, whereas less sampling points makes damage localization difficult. Effect of reduced spatial sampling is to underestimate the damage size i.e. the variation of spatial signal at the damaged location appears to be smoother.

4. The proposed damage identification method using wavelet can be applied in structural damage detection and quantification, when appropriate measuring methods are capable to sense the disturbances or curvatures caused by existence of damage or perturbation are used to get modal data and modal strain energy. The laser vibrometer instrument will be used to enhance the performance of this method by providing measurement with high spatial density and accuracy.

\section{FUNDING}

7 his research was financial supported by the Department of Science and Technology, India [Grant number ECR/2017/000512].

\section{REFERENCES}

[1] Cawley, P. and Adams, R.D. (1979). The location of defects in structures from measurements of natural frequencies. Journal of strain analysis, 14 (2), DOI.10.1243/03093247V142049

[2] Daubechies, I. (1992). Ten Lectures on Wavelets. Philadelphia, PA: SIAM. DOI.10.1137/1.9781611970104

[3] Mallat, S. and Hwang, W.L. (1992). Singularity detection and processing with wavelets. IEEE Transactions on Information Theory, 38(2), pp.617-643. DOI: 10.1109/18.119727

[4] Salawu, O.S. and Williams, C. (1993). Structural Damage Detection Using Experimental Modal Analysi Comparison of Some Methods, in Proc. of 11th International Modal Analysis Conference, pp.254-260

[5] Stubbs, N., Kim, J.T. and Farrar, C. (1995). Field verification of a non-destructive damage localization and severity estimation algorithm, Proceedings of SPIE - the International Society for Optical Engineering. Nashville: SPIE. DOI:10.3390/app7050497.

[6] Quan, W. and Xiaomin, D. (1999). Damage detection with spatial wavelets. International Journal of Solids and Structures, 36(23), pp.3443-3468. DOI.10.1016/S0020-7683(98)00152-8.

[7] Boulahbal et al., (1999). Amplitude and phase wavelet maps for the detection of cracks in geared systems. Mechanical Systems and Signal Processing, 13 (3), pp.423-436. DOI.10.1006/mssp.1998.1206.

[8] Angrisani, L., Daponte, P. and Apuzzo, M.D. (1999). A method for the automatic detection and measurement of transients. Part II: applications. Measurement 25(1), pp. 31-40. DOI.10.1016/S0263-2241(98)00064-5.

[9] Ratcliffe, C P. (2000). Frequency and curvature based experimental method for locating damage in structures, J. Vibration Acoustic, 122(3), pp.324-329. DOI.10.1115/1.1303121.

[10] Tong et al., (2001). Sensitivity analysis of crack detection in beams by wavelet technique. International Journal of Mechanical Sciences, 43(12), pp.2899-2910c.DOI. 10.1016/S0020-7403(01)00064-9.

[11] Douka et al., (2003). Crack identification in beams using wavelet analysis. International Journal of Solids and Structures, 40(13-14), pp.3557-3569. DOI.10.1016/S0020-7683(03)00147-1.

[12] Hani, M. and Hansang, K. (2003). Damage Detection in Concrete by Fourier and Wavelet analyses, Journal of Engineering Mechanics, 129 (5) DOI.10.1061/(ASCE)0733-9399(2003)129:5(571).

[13] Chang, C. and Chen, W. (2003). Vibration damage detection of a Timoshenko beam by spatial wavelet based approach. Applied Acoustics, 64(12), pp.1217-1240. DOI.10.1016/S0003-682X(03)00070-7.

[14] Loutridisa et al., (2004). Crack identification in double-cracked beams using wavelet analysis. Journal of Sound and Vibration, 277(4-5), pp.1025-1039, DOI.10.1016/j.jsv.2003.09.035. 
[15] Chang, C. and Chen, W. (2005). Detection of the location and size of cracks in the multiple cracked beam by spatial wavelet based approach. Mechanical Systems and Signal Processing, 19(1), pp.139-155.

DOI.10.1016/j.ymssp.2003.11.001.

[16] Rucka, M. and Wilde, K. (2006). Application of continuous wavelet transform in vibration based damage detection method for beams and plates. Journal of Sound and Vibration, 297(3-5), pp.536-550, DOI.10.1016/j.jsv.2006.04.015.

[17] Reddy, D.M. and Swarnamani, S. (2012). Damage Detection and Identification in Structures by Spatial Wavelet Based Approach. International Journal of Applied Science and Engineering, 1, pp.69-87.

[18] Reddy, D.M. and Swarnamani, S. (2012a). Application of the FRF curvature energy damage detection method to plate like structures. World Journal of Modeling and Simulation, 8(2), pp.147-153.

[19] Katunin, A and Holewik, F (2013). Crack identification in composite elements with non-linear geometry using spatial wavelet transform. Archives of civil and mechanical engineering, 13(3), pp. 287-296, DOI.10.1016/j.acme.2013.02.003.

[20] Khorram, A. Rezaeian, M.F. Nejad, B. (2013). Multiple cracks detection in a beam subjected to a moving load using wavelet analysis combined with factorial design. European Journal of Mechanics A/Solids 40, pp.97-113, DOI.10.1016/j.euromechsol.2012.12.012.

[21] Xiang, J., Matsumoto, T., Wang, Y., and Jiang, Z. (2013). Detect damages in conical shells using curvature mode shape and wavelet finite element method, International Journal of Mechanical Sciences, 66, pp. 83-93, DOI .10.1016 /j.ij mecsci.2012.10.010

[22] Katunin, A. (2014). Vibration-based spatial damage identification in honeycomb-core sandwich composite structures using wavelet analysis. Composite Structures, 118, pp.385-391. DOI.10.1016/ j.compstruct.2014.08.010.

[23] Mehrjoo, M., Khaji, N. and Ashtiany, M.G. (2014). New Timoshenko-cracked beam element and crack detection in beam like structures using genetic algorithm, Inverse Problems in Science and Engineering, 22 (3), pp. 359-382. DOI.10.1080/17415977.2013.788170

[24] Feng, K. and Li, Z. (2015). A novel superposed waveform method for damage detection of composite laminates, Nondestructive Testing and Evaluation, 31 (1), pp-61-76, DOI.10.1080/10589759.

[25] Katunin, A., Danczak, M. and Kostka, P. (2015). Automated identification and classification of internal defects in composite structures using computed tomography and 3D wavelet analysis. Archives of civil and mechanical engineering 15(2), pp. 436-448. DOI.10.1016/j.acme.2014.08.002

[26] Jaiswal, N.G. and Pande, D.W. (2015). Sensitizing the mode shapes of beam towards damage detection using curvature and wavelet transform. International journal of scientific \& technology research, 4(4), pp.266-272

[27] Diaferio,M and Sepe, V.(2016). Modal identification of damaged frames. Structural Control Health Monitoring, 23(1) pp. 82-102. DOI.10.1002/stc.1762

[28] Gholizad, A. and Safari, H. (2017). Damage identification of structures using experimental modal analysis and continuous wavelet transform, Numerical methods in civil engineering, 2(1), pp.61-71

[29] Janeliukstis, R., Rucevskis, S., Wesolowski, M., and Chate, A. (2017). Multiple damage identification in beam structure based on wavelet transform, Procedia Engineering 172, pp. 426-432. DOI.10.1016/j.proeng.2017.02.023

[30] Mardasi, A.G., Wu, N and Wu, C. (2018). Experimental study on the crack detection with optimized spatial wavelet analysis and windowing, Mechanical Systems and Signal processing 104, pp. 619-630.

DOI.10.1016/j.ymssp.2017.11.039.

[31] MATLAB (2018), The MathWorks, Inc., Natick, Release 2018a

[32] Abdulkareem, M., Bakhary, N., Vafaei, M., Noor, N and Samat, R.A. (2019). Experimental damage assessment of support condition for plate structures using wavelet transform, Journal of theoretical and applied mechanics, 57(2) pp. 501-518. DOI.10.15632/jtam-pl/105470.

[33] Akbari, J., Ahmadifarid, M. and Amiri, A.K. (2020). Multi crack detection wavelet transforms and energy signal techniques, Frattura ed Integrita strutturale, 14(52), pp. 269-281. DOI.10.3221/IGF-ESIS.52.21. 